\title{
Palm oil protects a-linolenic acid from rumen biohydrogenation and muscle oxidation in cashmere goat kids
}

Xue Wang ${ }^{1,2,3}$, Graeme B. Martin³ ${ }^{3}$ Qi Wen ${ }^{1}$, Shulin Liu', Yinhao Li', Binlin Shi', Xiaoyu Guo ${ }^{1}$, Yanli Zhao ${ }^{1}$, Yangdong Guo ${ }^{2}$ and Sumei Yan ${ }^{1 *}$

\begin{abstract}
Background: In ruminants, dietary C18:3n-3 can be lost through biohydrogenation in the rumen; and C18:3n-3 that by-passes the rumen still can be lost through oxidation in muscle, theoretically reducing the deposition of C18:3n-3, the substrate for synthesis of poly-unsaturated fatty acids (n-3 LCPUFA) in muscle. In vitro studies have shown that rumen hydrogenation of C18:3n-3 is reduced by supplementation with palm oil (rich in cis-9 C18:1). In addition, in hepatocytes, studies with neonatal rats have shown that cis-9 C18:1 inhibits the oxidation of C18:3n-3. It therefore seems likely that palm oil could reduce both rumen biohydrogenation of C18:3n-3 and muscle oxidation of C18:3n3. The present experiment tested whether the addition of palm oil to a linseed oil supplement for goat kids would prevent the losses of C18:3n-3 and thus improve the FA composition in two muscles, Longissimus dorsi and Biceps femoris. To investigate the processes involved, we studied the rumen bacterial communities and measured the mRNA expression of genes related to lipid metabolism in Longissimus dorsi. Sixty 4-month-old castrated male Albas white cashmere kids were randomly allocated among three dietary treatments. All three diets contained the same ingredients in the same proportions, but differed in their fat additives: palm oil (PMO), linseed oil (LSO) or mixed oil (MIX; 2 parts linseed oil plus 1 part palm oil on a weight basis).

Results: Compared with the LSO diet, the MIX diet decreased the relative abuandance of Pseudobutyrivibrio, a bacterial species that is positively related to the proportional loss rate of dietary C18:3n-3 and that has been reported to generate the ATP required for biohydrogenation (reflecting a decrease in the abundance of rumen bacteria that hydrogenate C18:3n-3 in MIX kids). In muscle, the MIX diet increased concentrations of C18:3n-3, C20:5n-3, C22:6n-3, and n-3 LCPUFA, and thus decreased the $n-6 / n-3$ ratio; decreased the mRNA expression of CPT1 $\beta$ (a gene associated with fatty acid oxidation) and increased the mRNA expression of FADS1 and FADS2 (genes associated with n-3 LCPUFA synthesis), compared with the LSO diet. Interestingly, compared to Longissimus dorsi, Biceps femoris had greater concentrations of PUFA, greater ratios of unsaturated fatty acids/saturated fatty acids (U/S), and poly-unsaturated fatty acids/saturated fatty acids (P/S), but a lesser concentration of saturated fatty acids (SFA).

(Continued on next page)
\end{abstract}

\footnotetext{
* Correspondence: yansmimau@163.com

${ }^{1}$ Inner Mongolia Key Laboratory of Animal Nutrition and Feed Science,

College of Animal Science, Inner Mongolia Agricultural University, Hohhot 010018, China

Full list of author information is available at the end of the article
}

(c) The Author(s). 2020 Open Access This article is licensed under a Creative Commons Attribution 4.0 International License, which permits use, sharing, adaptation, distribution and reproduction in any medium or format, as long as you give appropriate credit to the original author(s) and the source, provide a link to the Creative Commons licence, and indicate if changes were made. The images or other third party material in this article are included in the article's Creative Commons licence, unless indicated otherwise in a credit line to the material. If material is not included in the article's Creative Commons licence and your intended use is not permitted by statutory regulation or exceeds the permitted use, you will need to obtain permission directly from the copyright holder. To view a copy of this licence, visit http://creativecommons.org/licenses/by/4.0/ The Creative Commons Public Domain Dedication waiver (http://creativecommons.org/publicdomain/zero/1.0/) applies to the data made available in this article, unless otherwise stated in a credit line to the data. 


\begin{abstract}
(Continued from previous page)
Conclusions: In cashmere goat kids, a combination of linseed and palm oils in the diet increases the muscle concentration of n-3 LCPUFA, apparently by decreasing the relative abundance of rumen bacteria that are positively related to the proportional loss rate of dietary $\mathrm{C} 18: 3 \mathrm{n}-3$, by inhibiting mRNA expression of genes related to C18:3n-3 oxidation in muscle, and by up-regulating mRNA expression of genes related to n-3 LCPUFA synthesis in muscle, especially in Longissimus dorsi.
\end{abstract}

Keywords: Desaturases, Docosahexaenoic acid, Hydrogenation, Goats, Meat, Oleic acid, Oxidative stress

\section{Background}

The long chain $\mathrm{n}-3$ poly-unsaturated fatty acids (n-3 LCPUFA), such as C20:5n-3 and C22:6n-3, have a wide range of biological effects that have long been believed to be beneficial for human health $[1,2]$. An important dietary source of n-3 LCPUFA is meat from ruminants, so there have been many attempts to increase the muscle concentration of n-3 LCPUFA in livestock by feeding dietary supplements [3]. In theory, this outcome could be accomplished by feeding the animals with linseed oil because it is rich in C18:3n-3, the substrate for n-3 LCPUFA synthesis [4]. However, dietary C18:3n-3 can be hydrogenated extensively by rumen bacteria [5], potentially leading to a reduction in post-ruminal C18: 3n-3 flow. This problem might be overcome by feeding oils rich in cis-9 C18:1, as revealed by an in vitro rumen study in which palm oil was added to a basal diet - after $24 \mathrm{~h}$ incubation, it decreased C18:3n-3 biohydrogenation but enhanced cis-9 C18:1 biohydrogenation, in a doseresponsive manner [6]. However, the ruminal microbes involved in this process have not been identified.

The next challenge is that the ruminal "by-pass" C18: $3 n-3$ can be oxidized in the various tissues and organs that are involved in fatty acid (FA) metabolism [7], leading to a reduction in the tissue deposition of $\mathrm{C} 18: 3 \mathrm{n}-3$, and therefore the local synthesis of $n-3$ LCPUFA in muscle.

On the other hand, susceptibility to oxidative stress in mammals is increased by consumption of dietary $n-3$ PUFA $[8,9]$. In the liver, oxidative stress can reduce the gene expression and catalytic activity of $\Delta-5$ and $\Delta-6$ desaturases (FADS1 and FADS2), the most relevant enzymes in n-3 LCPUFA biosynthesis, thereby reducing the tissue levels of n-3 LCPUFA [10]. Again, in vitro studies have presented a possible solution - in a study with rat hepatocytes, the oxidative stability of $\mathrm{C} 18: 3 \mathrm{n}-3$ was improved by blending C18:3n-3 with cis-9 C18:1 [11].

Together, these observations suggest that more substrate and desaturases would become available for the synthesis of n-3 LCPUFA in vivo if the biohydrogenation and oxidation of C18:3n-3 could be reduced by blending linseed oil with palm oil in ruminant diets. Moreover, any changes in biohydrogenation pathways in the rumen would probably be explained by changes in the bacterial communities [5]. Therefore, using cashmere kids, we tested whether diets supplemented with a blend of linseed and palm oils increases the muscle concentration of n-3 LCPUFA more than linseed oil alone, and whether this outcome is mediated by i) a reduction in the abundance of bacteria that hydrogenate $\mathrm{C} 18: 3 \mathrm{n}-3$ in the rumen; ii) a decrease in mRNA expression of $C P T 1 \beta$ (a gene related to FA oxidation), and iii) an up-regulation of the mRNA expression of FADS1 and FADS2 in muscle.

\section{Methods}

\section{Animals, diets and feeding management}

This study was conducted on the Inner Mongolia White Cashmere Goat Breeding Farm, Wulan Town, Etuoke Banner, Ordos City, Inner Mongolia Autonomous Region, China $\left(39^{\circ} 12^{\prime} \mathrm{N} ; 107^{\circ} 97^{\prime} \mathrm{E}\right)$. Sixty 4-month-old castrated male kids (average body weight $18.6 \pm 0.1 \mathrm{~kg}$ ) were selected and randomly allocated among three groups, each of which comprised four units of five kids. All three diets contained the same ingredients in the same proportions, but their fat additives differed (Table 1): palm oil (PMO), linseed oil (LSO) or mixed oil (MIX; linseed oil blended with palm oil in a 2:1 ratio based on weight, providing $4.7 \%$ fat, 35\% C18:3n-3 and 20\% cis-9 C18:1). For blending, palm oil (Jiali, Shanghai, China) and linseed oil (Mengyue Xiang Biotechnology Co., Ltd., Inner Mongolia, China) were removed from frozen storage and placed in direct sunlight (about $25^{\circ} \mathrm{C}$ ) to defrost, then mixed in a stainless steel vessel.

The diets were prepared by manually blending the oil thoroughly into the ground concentrate to ensure homogenous distribution throughout the ration. The diets were prepared fresh twice each day and were offered as a total mixed ration (TMR) in two equal meals at 08:30 and 16:30 h. The kids were given free access to drinking water. The diets were fed for 104 $\mathrm{d}$, consisting of $14 \mathrm{~d}$ for adaptation followed by $90 \mathrm{~d}$ of treatment. The treatment period was divided into early $(1-30 \mathrm{~d})$, middle $(31-60 \mathrm{~d})$ and late periods (61-90 d) so the amount and composition of diet offered could be increased to meet the needs of cashmere kids as they grow, according to the feeding 
Table 1 Composition and analysis of experimental diets fed to cashmere goat kids

\begin{tabular}{|c|c|c|c|c|c|c|c|c|c|}
\hline \multirow[t]{2}{*}{ Item } & \multicolumn{3}{|c|}{ Day 1-30 } & \multicolumn{3}{|c|}{ Day 31-60 } & \multicolumn{3}{|c|}{ Day 61-90 } \\
\hline & $\mathrm{PMO}$ & LSO & MIX & $\mathrm{PMO}$ & LSO & MIX & $\mathrm{PMO}$ & LSO & MIX \\
\hline \multicolumn{10}{|l|}{ Ingredient (\% air dry basis) } \\
\hline Alfalfa hay particles & 25.00 & 25.00 & 25.00 & 15.00 & 15.00 & 15.00 & 12.50 & 12.50 & 12.50 \\
\hline Maize straw particles & 5.00 & 5.00 & 5.00 & 20.00 & 20.00 & 20.00 & 25.00 & 25.00 & 25.00 \\
\hline Tall oat grass particles & 20.00 & 20.00 & 20.00 & 15.00 & 15.00 & 15.00 & 12.50 & 12.50 & 12.50 \\
\hline Corn & 23.37 & 23.37 & 23.37 & 30.40 & 30.40 & 30.40 & 29.90 & 29.90 & 29.90 \\
\hline Soybean meal & 10.50 & 10.50 & 10.50 & 11.40 & 11.40 & 11.40 & 10.40 & 10.40 & 10.40 \\
\hline Distillers dried grains with solubles & 7.24 & 7.24 & 7.24 & 0.50 & 0.50 & 0.50 & 0.50 & 0.50 & 0.50 \\
\hline Flax cake & 4.80 & 4.80 & 4.80 & 3.50 & 3.50 & 3.50 & 4.50 & 4.50 & 4.50 \\
\hline Linseed oil & 0.00 & 2.00 & 1.33 & 0.00 & 2.00 & 1.33 & 0.00 & 2.50 & 1.67 \\
\hline Palm oil & 2.00 & 0.00 & 0.67 & 2.00 & 0.00 & 0.67 & 2.50 & 0.00 & 0.83 \\
\hline Premix $^{a}$ & 0.50 & 0.50 & 0.50 & 0.50 & 0.50 & 0.50 & 0.50 & 0.50 & 0.50 \\
\hline Calcium carbonate & 0.20 & 0.20 & 0.20 & 0.20 & 0.20 & 0.20 & 0.20 & 0.20 & 0.20 \\
\hline $\mathrm{CaHPO}_{4}$ & 0.20 & 0.20 & 0.20 & 0.20 & 0.20 & 0.20 & 0.20 & 0.20 & 0.20 \\
\hline Sodium chloride & 0.54 & 0.54 & 0.54 & 0.50 & 0.50 & 0.50 & 0.50 & 0.50 & 0.50 \\
\hline Sodium bicarbonate & 0.35 & 0.35 & 0.35 & 0.80 & 0.80 & 0.80 & 0.80 & 0.80 & 0.80 \\
\hline Magnesium oxide & 0.30 & 0.30 & 0.30 & 0.00 & 0.00 & 0.00 & 0.00 & 0.00 & 0.00 \\
\hline \multicolumn{10}{|l|}{ Chemical composition } \\
\hline Digestible energy ${ }^{\mathrm{b}}, \mathrm{MJ} / \mathrm{kg}$ DM & 12.9 & 13.1 & 13.0 & 12.8 & 13.0 & 12.9 & 12.8 & 13.1 & 13.0 \\
\hline$C P, g / k g ~ D M$ & 188.2 & 188.1 & 188.1 & 158.8 & 158.7 & 158.8 & 151.5 & 151.4 & 151.4 \\
\hline Ether extract, $\mathrm{g} / \mathrm{kg} \mathrm{DM}$ & 54.1 & 51.8 & 52.6 & 46.0 & 43.7 & 44.4 & 49.1 & 46.3 & 47.2 \\
\hline NDF, g/kg DM & 430.3 & 431.2 & 431.1 & 427.6 & 427.4 & 427.5 & 436.3 & 436.1 & 436.1 \\
\hline$A D F, g / k g ~ D M$ & 230.7 & 231.7 & 231.0 & 235.2 & 235.3 & 235.2 & 240.5 & 240.3 & 240.2 \\
\hline Calcium, g/kg DM & 11.1 & 11.1 & 11.0 & 10.8 & 10.9 & 10.8 & 10.7 & 10.7 & 10.7 \\
\hline Phosphorus, g/kg DM & 4.7 & 4.7 & 4.7 & 4.5 & 4.4 & 4.5 & 4.3 & 4.2 & 4.3 \\
\hline \multicolumn{10}{|l|}{ Fatty acids ( $\%$ of total) ${ }^{c}$} \\
\hline C16:0 & 26.69 & 10.98 & 16.25 & 25.88 & 9.28 & 14.77 & 26.88 & 8.50 & 14.61 \\
\hline C16:1 & 0.50 & 0.49 & 0.49 & 0.51 & 0.50 & 0.50 & 0.49 & 0.48 & 0.48 \\
\hline C18:0 & 2.64 & 3.18 & 3.00 & 2.52 & 3.10 & 2.91 & 2.47 & 3.10 & 2.89 \\
\hline trans-9 C18:1 & 0.39 & 0.39 & 0.39 & 0.38 & 0.39 & 0.39 & 0.37 & 0.38 & 0.37 \\
\hline cis-9 C18:1 & 29.29 & 15.19 & 19.92 & 29.22 & 14.33 & 19.25 & 31.04 & 14.55 & 20.04 \\
\hline$C 18: 2 n-6 t$ & 0.46 & 0.26 & 0.33 & 0.44 & 0.23 & 0.30 & 0.42 & 0.19 & 0.27 \\
\hline$c 18: 2 n-6 c$ & 19.22 & 20.65 & 20.17 & 22.53 & 24.04 & 23.54 & 21.06 & 22.74 & 22.18 \\
\hline C18:3n-3 & 8.58 & 35.59 & 26.53 & 6.40 & 34.91 & 25.50 & 5.73 & 37.30 & 26.81 \\
\hline$C 20: 5 n-3$ & 0.35 & 0.35 & 0.35 & 0.36 & 0.36 & 0.36 & 0.31 & 0.31 & 0.31 \\
\hline$C 22: 6 n-3$ & 0.66 & 0.36 & 0.46 & 0.73 & 0.42 & 0.52 & 0.73 & 0.38 & 0.50 \\
\hline Saturated fatty acids & 35.99 & 20.30 & 25.57 & 35.09 & 18.52 & 24.00 & 35.73 & 17.38 & 23.48 \\
\hline Monounaturated fatty acids & 32.10 & 19.27 & 23.57 & 32.06 & 18.51 & 22.99 & 33.77 & 18.77 & 23.75 \\
\hline Polyunsaturated fatty acids & 32.08 & 60.43 & 50.92 & 33.03 & 62.97 & 53.08 & 30.71 & 63.86 & 52.84 \\
\hline
\end{tabular}

a Provided per kg of premix: iron (Fe) $4 \mathrm{~g}$, copper (Cu) $0.8 \mathrm{~g}$, zinc (Zn) $5 \mathrm{~g}$, manganese (Mn) $3 \mathrm{~g}$, iodine (I) $30 \mathrm{mg}$, selenium (Se) $30 \mathrm{mg}$, cobalt (Co) $25 \mathrm{mg}$, vitamin A (VA) 600,000 IU, vitamin D (VD $\left.\mathrm{VD}_{3}\right)$ 250,000 IU, vitamin E (VE) 1,250 IU, vitamin K (VK 3 ) $180 \mathrm{mg}$, vitamin $\mathrm{B}_{1}\left(\mathrm{VB}_{1}\right) 35 \mathrm{mg}$, vitamin $\mathrm{B}_{2}\left(\mathrm{VB}_{2}\right) 850 \mathrm{mg}$, vitamin $\mathrm{B}_{6}\left(\mathrm{VB}_{6}\right) 90$ $\mathrm{mg}$, nicotinic acid 2,200 mg, D-pantothenic acid 1,700 mg, vitamin $B_{12}\left(\mathrm{VB}_{12}\right) 3 \mathrm{mg}$, biotin $14 \mathrm{mg}$, folic acid $150 \mathrm{mg}$

${ }^{b}$ Digestible energy is calculated based on the ingredients of the diet and their digestible energy content, not based on the actual dry matter intake

c Total fatty acids $=$ saturated fatty acids $(6: 0+8: 0+10: 0+11: 0+12: 0+13: 0+14: 0+15: 0+16: 0+17: 0+18: 0+20: 0+21: 0+22: 0+23: 0+24: 0)+$ monounsaturated fatty acids $(14: 1+15: 1+16: 1+17: 1+$ trans-9 18:1 + cis-9 18:1 + 20:1 + 22:1 + 24:1) + polyunsaturated fatty acids $(18: 2 n-6 t+18: 2 n-6 c+18: 3 n-6+20: 2 n-6+20: 3 n-6+$ $20: 4 n-6+22: 2 n-6+18: 3 n-3+20: 3 n-3+20: 5 n-3+22: 6 n-3)$

PMO palm oil diet, LSO linseed oil diet, MIX mixed oil diet 
standard of meat-producing sheep and goats (China, NY/T816, 2004 [12]; Table 1).

\section{Sampling and slaughtering procedures}

To estimate dry matter intake for five kids in each pen, refusals were collected and weighed $30 \mathrm{~min}$ before each feeding, at 08:00 h daily. After weighing, the refusals were evenly sprinkled on the surface of the fresh TMR and were re-fed to the kids. The amount of feed offered was adjusted daily in the morning to ensure a $10 \%$ refusal (as fed basis). Samples of TMR were collected at the beginning of each period and stored at $-20^{\circ} \mathrm{C}$ for chemical analysis. At the end of the experiment, two kids from each experimental unit (total 8 per treatment) were randomly selected and slaughtered by exsanguination. Before slaughter, the kids were prevented from consuming feed for $24 \mathrm{~h}$ and from drinking for $2 \mathrm{~h}$. Immediately after death, the rumen was dissected and digesta was squeezed through two layers of cheesecloth. Left Longissimus dorsi and left Biceps femoris were collected. Subsamples of rumen liquid $(500 \mathrm{~mL})$ and muscle $(100 \mathrm{~g})$ were snap frozen in liquid $\mathrm{N}_{2}$ and stored at $-80^{\circ} \mathrm{C}$ until analysis.

\section{Chemical analyses \\ Analysis of feed}

Samples of dietary ingredients were analyzed for DM (method 930.15), ether extract (method 920.39), CP $(\mathrm{N} \times 6.25$; method 984.13$)$, calcium and phosphorous (method 935.13) according to AOAC [13]. Neutral detergent fibre and ADF were determined according to the methods described by Van Soest et al. [14] with an Ankom 220 Fiber Analyser (Ankom Co., USA) and were expressed inclusive of residual ash. Heat stable amylase was not used in the NDF determination.

\section{Measurement of FA}

Fatty acid methyl esters were produced from samples of feed, plasma, muscle, and rumen liquid, according to the method of O'Fallon et al. [15], and were analyzed as described previously [16].

\section{RNA extraction and real-time PCR}

For Longissimus dorsi only, total RNA was extracted from $0.5 \mathrm{~g}$ samples of frozen tissue using the RNAiso Reagent (TaKaRa, Dalian, China) according to the manufacturer's recommendations. The concentration, purity and integrity of the RNA were assessed by $2 \%$ agarose gel electrophoresis and a microplate reader (Synergy H4, BioTek, USA) at 260/280 nm (OD260/OD280 $=1.8-2.0)$. Synthesis of first-strand cDNA and quantitative realtime PCR were performed as described previously [16, $17])$, with the same primer pair sequences, and the same three gene references ( $\beta$-2-microglobulin, tyrosine 3- monooxygenase, $\beta$-actin). The primers used are presented in Supplementary Table S1. The efficiency of PCR amplification for each gene was calculated with the standard curve method $\left(E=10^{-1} /\right.$ slope $)$. The efficiency of PCR amplification for all genes was between 0.980.99 (Supplementary Table S1). The $2^{-\Delta \Delta \mathrm{Ct}}$ method was used to analyze the qPCR data [18]. The qPCR data were normalized using the geometric mean $\mathrm{Ct}$ of the three reference genes [19].

\section{Metagenomic analyses \\ DNA extraction}

Microbial DNA was extracted from rumen samples from six of the eight slaughtered kids in each group, using the E.Z.N.A. soil DNA Kit (Omega Biotek, Norcross, GA, U.S.) according to the manufacturer's protocols. DNA integrity was evaluated using $1 \%$ agarose gel electrophoresis. The DNA was diluted to $1 \mathrm{ng} / \mu \mathrm{L}$ using sterile water. The extraction and the metagenomic analyses were conducted in Inner Mongolia Agriculture University.

\section{Hiseq sequencing and data analysis}

Polymerase chain reaction was used to amplify the V4 region of the bacterial $16 \mathrm{~S}$ rRNA gene using the universal primers 515F (5'-GTGCCAGCMGCCGCGGTAA$\left.3^{\prime}\right)$ and 806R (5'-GGACTACHVGGTWTCTAAT-3'; with the barcode [20]. The forward primer contained 6base barcode sequences. The reaction was carried out with Phusion ${ }^{\circ}$ High-Fidelity PCR Master Mix (New England Biolabs). The PCR reaction mixture $(30 \mu \mathrm{L})$ contained $10 \mu \mathrm{L}$ DNA template, $15 \mu \mathrm{L}$ of Phusion Master Mix ( $2 \times$ ), $1.5 \mu \mathrm{L}$ of each primer (total $6 \mu \mathrm{mol} / \mathrm{L}$ and $2 \mu \mathrm{L}$ of double-distilled $\mathrm{H}_{2} \mathrm{O}$. The PCR was performed under the following conditions: $98^{\circ} \mathrm{C}$ for $1 \mathrm{~min}$, followed by 30 cycles of $98^{\circ} \mathrm{C}$ for $10 \mathrm{~s}, 50^{\circ} \mathrm{C}$ for $30 \mathrm{~s}$, and $72{ }^{\circ} \mathrm{C}$ for $30 \mathrm{~s}$, and a final elongation step of $72{ }^{\circ} \mathrm{C}$ for $5 \mathrm{~min}$. The same volume of $1 \times$ loading buffer (contained SYB green) was mixed with the PCR products and the mixture was subjected to electrophoresis on 2\% agarose gel. Samples with a bright main strip between 400 and 450 bp were chosen for further analysis. The PCR products were mixed in equimolar amounts and then purified with a Qiagen Gel Extraction Kit (Qiagen, Germany). Sequencing libraries were generated using TruSeq ${ }^{\circ}$ DNA PCRFree Sample Preparation Kit (Illumina, USA), following the manufacturer's recommendations, and index codes were added. Library quality was assessed on the Qubit@ 2.0 Fluorometer (Thermo Scientific) and Agilent Bioanalyzer 2100 system. Finally, the library was sequenced on an Illumina HiSeq 2500 platform and 250 bp paired-end reads were generated.

The generated raw sequences were processed using FLASH and Trimmomatic to merge the paired-end 
sequences and remove low quality reads with the following criteria: i) The reads were truncated at any site receiving an average quality score $<20$ over a 50 -bp sliding window; ii) Primer matching allowed 2-nucleotide mismatching, and reads containing ambiguous bases were removed; iii) Sequences with an overlap longer than 10 bp were merged according to their overlap sequence. Operational taxonomic units (OTUs) were clustered with a $97 \%$ similarity cut-off using UPARSE (version 7.1 http://drive5.com/uparse/) and chimeric sequences were identified and removed using UCHIME. The taxonomy of each $16 \mathrm{~S}$ rRNA gene sequence was analyzed with the RDP Classifier algorithm (http://rdp.cme.msu.edu/) against the Silva 128 16S rRNA database (Release128 http://www.arb-silva.de) using a confidence threshold of $70 \%$. Bacterial diversity was measured using the QIIME pipeline based on the OTUs [21]. To eliminate variation among individual kids and thus allow all samples to be compared at the same OTU sequence number, OTU abundance information was normalized using a standard sequence number corresponding to the sample with the least sequences. Subsequent analyses were performed on this output-normalized data.

\section{Statistical analysis}

The data for muscle FA composition were analyzed using PROC MIXED of SAS (version 9.2, SAS Institute Inc., Cary, NC). The MIXED statistical model used for analysis was $\mathrm{y}_{\mathrm{ijkl}}=\mu+\mathrm{L}_{\mathrm{i}}+\mathrm{E}_{\mathrm{j}}+\mathrm{LE}_{\mathrm{ij}}+\mathrm{A}_{\mathrm{ijk}}+\mathrm{T}_{1}+\mathrm{TL}_{\mathrm{il}}+$ $\mathrm{TE}_{\mathrm{jl}}+\mathrm{TLE}_{\mathrm{ijl}}+\varepsilon_{\mathrm{ijkl}}$ where $\mathrm{y}_{\mathrm{ijkl}}$ was the dependent, continuous variable, $\mu$ is the overall mean, $L_{i}$ was the fixed effect of diet ( $i=$ palm oil, linseed oil or mixed oil), $E_{j}$ was the fixed effect of tissue $(\mathrm{j}=$ longissimus dorsi or $b i$ ceps femoris), $\mathrm{A}_{\mathrm{ijk}}$ was the random effect of the $\mathrm{k}^{\text {th }}$ pen in the $\mathrm{it}^{\text {th }}$ combination of diet and tissue, $\mathrm{T}_{1}$ was the random effect of pen, the two- and three-way interactions of diet, tissue and pen were all considered fixed effects, and $\varepsilon_{\mathrm{ijkl}}$ was the residual error. Pen was considered as the experimental unit. Tissue was a repeated measurement. Least square means were compared using LSD and statistical differences were declared significant at $P<0.05$, and tendencies are discussed at $0.05 \leq P<0.10$.

Dry matter intake, rumen FA, plasma FA, and mRNA expression were analyzed using the MIXED procedure. The statistical model included treatment as fixed effects, and pens were added to the model as random effects. Specifically, the model used to study DMI consider 4 replicates (number of pens), each with 1 observation; rumen FA, plasma FA, and mRNA expression consider 4 replicates (number of pens), each with 2 observations (number of goats), for each treatment. The effects of fixed factors were declared significant at $P<0.05$, and tendencies are discussed at $0.05 \leq P<0.10$.
Multivariate analysis was carried out using $\mathrm{R}$ software with the nonparametric MANOVA (Adonis) add-on. Adonis was performed on the Weighted Unifrac distances to assess the significance of differences in bacterial community structure across treatments at a significance level of $\alpha=0.05$ based on 9999 possible permutations. Non-metric multidimensional scaling (nMDS) plots were constructed to visualize the data. The ternary plot was created with GGTERN. For indices of bacterial diversity, ANOVA and post hoc, Tukey HSD tests were carried out. The results are presented as the mean and standard error of the mean (SEM). Data means were considered significantly different at $P<0.05$.

The rates of reduction in C18:3n-3 and cis-9 C18:1 from dietary values ( $\mathrm{d} 61-90)$ to rumen values, were considered to reflect hydrogenation [6, 22-24]. The rate of increment in the proportion of C18:0 from diet (d 61-90) to rumen was considered to reflect synthesis. The six rumen samples used for analysis of bacterial community structure in each group were also used to calculate the rates of reduction and increment in FAs. ANOVA and post hoc Tukey HSD tests were carried out. Spearman correlation analysis was used to relate the abundance of the top 45 bacterial genera and the rate of hydrogenation of dietary C18:3n-3 and cis-9 C18:1, and the rate of synthesis of $\mathrm{C} 18: 0$, using $\mathrm{R}$ (pheatmap package). Only correlations with $P<0.05$ for the linear model were considered as significant.

\section{Results}

\section{Rumen FA composition}

Compared with the LSO diet, the PMO or MIX diets increased $(P<0.05)$ the rumen proportion of $C 16: 0$, but decreased the proportion of C18:3n-3 $(P<0.05)$. The rumen $\mathrm{C} 16: 0$ proportion did not differ $(P \geq 0.10)$ between the PMO and MIX treatments (Table 2), but the C18:3n-3 value was greater in MIX-fed rumen than in PMO-fed rumen $(P<0.05)$. Rumen proportion of cis-9 C18:1 was reduced $(P<0.05)$ in LSO kids compared with PMO kids. The cis-9 C18:1 values for MIX kids did not differ $(P \geq 0.10)$ from those for either PMO or LSO kids. Rumen proportions of $\mathrm{C} 21: 0$ and $\mathrm{C} 22: 1$ were reduced $(P<0.05)$ whereas the proportions of C17:1 $(P=0.067)$, C24:1 $(P=0.058)$, C20:2n-6 $(P=0.070)$ only tended to decrease in MIX kids compared with PMO kids. The proportions of C21:0, C22:1, C17:1, C24:1, and C20:2n-6 for LSO kids did not differ $(P \geq 0.10)$ from those for either PMO or MIX kids. The proportion of C18:2n- $6 c$ tended to increase in MIX kids compared with PMO kids $(P=0.098)$, but the value for LSO kids did not differ $(P \geq 0.10)$ from those for either PMO or MIX kids.

\section{Muscle FA composition}

There were significant interactions $(P<0.05)$ between oil type and muscle for concentrations of C21:0, C17:1, 
Table 2 Fatty acid profiles (percentage of total identified fatty acids methyl esters) in rumen of kids fed diets containing oil supplements

\begin{tabular}{|c|c|c|c|c|c|}
\hline Fatty acid & PMO & LSO & MIX & SEM & $P$-value \\
\hline \multicolumn{6}{|l|}{ Saturated fatty acids } \\
\hline $\mathrm{C} 10: 0$ & 1.57 & 1.58 & 1.42 & 0.107 & 0.526 \\
\hline $\mathrm{C} 12: 0$ & 2.02 & 2.20 & 2.04 & 0.09 & 0.408 \\
\hline C13:0 & 0.96 & 1.02 & 0.87 & 0.049 & 0.150 \\
\hline C14:0 & 3.99 & 3.74 & 3.59 & 0.162 & 0.331 \\
\hline C15:0 & 2.03 & 2.15 & 2.22 & 0.095 & 0.465 \\
\hline C16:0 & $15.27^{\mathrm{a}}$ & $13.65^{b}$ & $14.81^{\mathrm{a}}$ & 0.171 & $<.001$ \\
\hline $\mathrm{C} 17: 0$ & 2.00 & 1.87 & 1.92 & 0.072 & 0.451 \\
\hline C18:0 & 16.72 & 18.21 & 18.86 & 0.535 & 0.103 \\
\hline $\mathrm{C} 20: 0$ & 2.53 & 2.36 & 2.4 & 0.06 & 0.346 \\
\hline C21:0 & $0.90^{\mathrm{a}}$ & $0.86^{\mathrm{ab}}$ & $0.72^{\mathrm{b}}$ & 0.042 & 0.046 \\
\hline $\mathrm{C} 22: 0$ & 2.26 & 1.93 & 1.96 & 0.129 & 0.205 \\
\hline C23:0 & 0.82 & 0.85 & 0.70 & 0.049 & 0.142 \\
\hline C24:0 & 2.04 & 1.97 & 1.89 & 0.075 & 0.436 \\
\hline \multicolumn{6}{|l|}{ Monounsaturated fatty acids } \\
\hline C14:1 & 1.62 & 1.62 & 1.66 & 0.061 & 0.896 \\
\hline C15:1 & 0.73 & 0.74 & 0.79 & 0.043 & 0.556 \\
\hline C16:1 & 1.98 & 1.79 & 1.98 & 0.103 & 0.399 \\
\hline C17:1 & 1.14 & 0.90 & 0.75 & 0.094 & 0.067 \\
\hline tran-9 18:1 & 8.82 & 10.69 & 9.94 & 0.469 & 0.149 \\
\hline cis-9 C18:1 & $11.44^{\mathrm{a}}$ & $9.35^{\mathrm{b}}$ & $10.45^{\mathrm{ab}}$ & 0.342 & 0.009 \\
\hline C20:1 & 1.12 & 0.94 & 0.97 & 0.079 & 0.295 \\
\hline $\mathrm{C} 22: 1$ & $0.90^{\mathrm{a}}$ & $0.87^{\mathrm{ab}}$ & $0.71^{b}$ & 0.048 & 0.040 \\
\hline C24:1 & 0.96 & 0.89 & 0.76 & 0.046 & 0.058 \\
\hline \multicolumn{6}{|l|}{ n-6 Polyunsaturated fatty acids } \\
\hline $\mathrm{C} 18: 2 \mathrm{n}-6 t$ & 0.88 & 0.83 & 0.75 & 0.034 & 0.151 \\
\hline$C 18: 2 n-6 c$ & 4.76 & 5.65 & 6.14 & 0.306 & 0.098 \\
\hline$C 18: 3 n-6$ & 0.87 & 0.85 & 0.83 & 0.039 & 0.808 \\
\hline$C 20: 2 n-6$ & 0.88 & 0.82 & 0.71 & 0.041 & 0.070 \\
\hline$C 20: 3 n-6$ & 0.79 & 0.8 & 0.73 & 0.042 & 0.444 \\
\hline$C 20: 4 n-6$ & 0.85 & 0.86 & 0.79 & 0.042 & 0.469 \\
\hline$C 22: 2 n-6$ & 0.88 & 0.84 & 0.69 & 0.046 & 0.045 \\
\hline \multicolumn{6}{|l|}{ n-3 Polyunsaturated fatty acids } \\
\hline C18:3n-3 & $1.36^{\mathrm{c}}$ & $2.15^{\mathrm{a}}$ & $1.71^{\mathrm{b}}$ & 0.050 & $<.001$ \\
\hline$C 20: 3 n-3$ & 0.79 & 0.81 & 0.71 & 0.053 & 0.720 \\
\hline$C 20: 5 n-3$ & 0.83 & 0.82 & 0.70 & 0.048 & 0.200 \\
\hline$C 22: 6 n-3$ & 0.86 & 0.89 & 0.76 & 0.056 & 0.302 \\
\hline Total fat (\% w/w of rumen liquid) & 0.015 & 0.016 & 0.014 & 0.001 & 0.582 \\
\hline \multicolumn{6}{|c|}{ Proportional loss rate of dietary fatty acids, $\%$} \\
\hline cis-9 C18:1 & $63.14^{\mathrm{a}}$ & $35.74^{c}$ & $47.85^{\mathrm{b}}$ & 1.04 & $<.001$ \\
\hline C18:3n-3 & $76.42^{c}$ & $94.65^{\mathrm{a}}$ & $92.96^{\mathrm{b}}$ & 0.33 & $<.001$ \\
\hline \multicolumn{6}{|c|}{ Proportional increase rate of dietary fatty acids, $\%$} \\
\hline C18:0 & $576.85^{\mathrm{a}}$ & $488.92^{\mathrm{b}}$ & $559.63^{\mathrm{a}}$ & 18.29 & 0.009 \\
\hline
\end{tabular}


Table 2 Fatty acid profiles (percentage of total identified fatty acids methyl esters) in rumen of kids fed diets containing oil supplements (Continued)

\begin{tabular}{llllll}
\hline Fatty acid & PMO & LSO & MIX & SEM & $P$-value \\
\hline Dry matter intake, kg per day per pen & 4.15 & 4.30 & 3.70 & 0.35 & 0.478 \\
\hline PMO palm
\end{tabular}

PMO palm oil diet, $L S O$ linseed oil diet, MIX mixed oil diet

${ }^{\mathrm{a}-\mathrm{c}}$ Means within the same row followed by the same superscript letters are not significantly different at $P<0.05$

C18:2n-6t, C18:3n-6, C20:2n-6, C18:3n-3, C22:6n-3, and the $n-6 / n-3$ ratio (Table 3 ). For all dietary treatments, the values for $C 18: 2 n-6 t$ concentration and $n-6 / n-3$ ratio were significantly greater $(P<0.05)$ in Biceps femoris than in Longissimus dorsi. Values for C18:3n-6 concentration and C20:2n-6 in Biceps femoris were significantly lower $(P<0.05)$ with MIX than with the other treatments. The highest $\mathrm{C} 21: 0$ concentration was observed in Biceps femoris with LSO treatment. The lowest C17:1 concentration was observed in Longissimus dorsi with PMO treatment. The lowest C18:3n-3 concentrations were observed in both muscles with PMO treatment, while the highest C18:3n-3 concentrations were observed in Biceps femoris with MIX treatment, and in $\mathrm{Bi}$ ceps femoris with LSO treatment. The concentration of C22:6n-3 was significantly higher in Longissimus dorsi with LSO treatment, and in Longissimus dorsi with MIX treatment $(P<0.05)$.

Significant main effects are also shown in Table 3. Compared with Biceps femoris, total fat content tended to be greater in Longissimus dorsi $(P=0.066)$. Dietary supplementation with LSO or MIX increased the muscle concentrations of $\mathrm{C} 18: 3 \mathrm{n}-3$ and n-3 PUFA $(P<0.05)$, but decreased the muscle concentration of C16:1 $(P<0.05)$ and the $n-6 / n-3$ ratio $(P<0.05)$, and tended to decrease the muscle concentration of MUFA $(P=0.066)$, compared with PMO. The muscle concentrations of those FAs did not differ $(P \geq 0.10)$ between kids fed the LSO and MIX diets.

Muscle concentrations of $\mathrm{C} 20: 5 n-3$ were greater $(P<$ $0.05)$ and concentrations of n-3 LCPUFA tended to be greater $(P=0.098)$, in MIX kids compared with PMO kids, but the value for LSO kids did not differ from those for either PMO or MIX kids $(P \geq 0.10)$. Diets containing PMO or LSO alone reduced the concentration of $\mathrm{C} 22$ : 6n-3 compared with the MIX diet $(P<0.05)$. Muscle concentration of $\mathrm{C} 22: 6 \mathrm{n}-3$ did not differ between kids fed LSO or PMO alone $(P \geq 0.10)$. Muscle concentrations of C15:0, C18:2n-6t, C21:0, and C20:1 were greater in LSO-fed kids compared with PMO and MIX-fed kids $(P<0.05)$, but did not differ $(P \geq 0.10)$ between PMO and MIX kids. Muscle concentrations of C18:3n- 6 and C20:2n-6 were lower in MIX-fed kids than in LSO-fed kids $(P<0.05)$. The $C 18: 3 n-6$ and $C 20: 2 n-6$ values for PMO kids did not differ $(P \geq 0.10)$ from those for either LSO or MIX kids. Compared with PMO-fed kids, muscle concentration of C22:2n-6 were lower in LSO-fed kids
$(P<0.05)$, but the value for MIX kids did not differ from those for either PMO kids or LSO kids $(P \geq 0.10)$.

As shown in Table 3, compared with Biceps femoris, Longissimus dorsi concentrations of C17:0, C18:0, cis-9 C18:1, C20:2n-6, C22:2n-6, saturated fatty acids (SFA) and monounsaturated fatty acids (MUFA) were greater $(P<0.05)$, and the concentration of $C 18: 3 n-6$ tended to be greater $(P=0.061)$, whereas the concentrations of C10:0, C12:0, C13:0, C14:0, C21:0, C22:0, C14:1, C15:1, C16:1, C20:1, C24:1, C18:2n-6c, C20:4n-6, C18:3n-3, C20:5n-3, PUFA, n-6 PUFA, and n-6 LCPUFA were lower, as were the ratios for $n-6 / n-3$, unsaturated fatty acid/saturated fatty acid (U/S), and polyunsaturated fatty acid/saturated fatty acid $(\mathrm{P} / \mathrm{S} ; \mathrm{P}<0.05)$.

\section{Plasma FA composition}

Compared with the LSO diet, supplementation with PMO increased $(P<0.05)$ the plasma proportions of C16:0 and cis-9 18:1, and tended to increase the proportions of $\mathrm{C} 16: 1(P=0.063)$ and MUFA $(P=0.081)$, but decreased $(P<0.05)$ the plasma proportions of $\mathrm{C} 21: 0$ and PUFA (Table 4). Plasma proportions of C18:3n-3, C20:5n-3, C22:6n-3, n-3 PUFA, n-3 LCPUFA were reduced $(P<0.05)$, but the $n-6 / n-3$ ratio was increased $(P<0.05)$ in PMO kids compared with LSO and MIX kids. The values of C18:3n-3, C20:5n-3, C22:6n-3, n-3 PUFA, n-3 LCPUFA, and the $n-6 / n-3$ ratio did not differ $(P \geq 0.10)$ between kids fed the LSO and MIX diets. Plasma proportion of $\mathrm{C} 20: 1 \mathrm{n}-9$ was increased $(P<0.05)$ in LSO kids compared with PMO and MIX kids. The value of $C 20: 1 n-9$ did not differ $(P \geq 0.10)$ between kids fed the PMO and MIX diets.

\section{mRNA expression}

The relative mRNA expression of genes in Longissimus dorsi is presented in Fig. 1. In comparison to PMO, mRNA expression of fatty acid synthetase (FAS) was greater $(P<0.05)$ with both the LSO and MIX treatments, with no difference $(P \geq 0.10)$ between MIX and LSO kids. In comparison to the LSO treatment, mRNA expression of carnitine palmitoyltransferase I $(C P T 1 \beta)$ was lower with the PMO and MIX treatments $(P<0.05)$, and mRNA expression of CPT1 $\beta$ was greater with the MIX treatment than with the PMO treatment $(P<0.05)$. Kids fed the mixed oil diet showed greater mRNA expression of FADS1 and FADS2 than PMO-fed kids, but 
Table 3 Fatty acid profiles (percentage of total identified fatty acids methyl esters) in muscles of kids fed diets containing oil supplements

\begin{tabular}{|c|c|c|c|c|c|c|c|c|c|c|}
\hline & \multicolumn{3}{|c|}{ Longissimus dorsi } & \multicolumn{3}{|c|}{ Biceps femoris } & \multirow{2}{*}{$\begin{array}{l}\text { SEM } \\
\text { main } \\
\text { effects }\end{array}$} & \multicolumn{3}{|l|}{$P$-value } \\
\hline & $\mathrm{PMO}$ & LSO & MIX & $\mathrm{PMO}$ & LSO & MIX & & Diet & Tissue & Diet $\times$ Tissue \\
\hline Total fat content (g/100 g fresh sample) & 2.92 & 3.05 & 2.78 & 2.57 & 2.55 & 2.53 & 0.23 & 0.817 & 0.066 & 0.884 \\
\hline \multicolumn{11}{|l|}{ Saturated fatty acids } \\
\hline $\mathrm{C} 10: 0$ & 0.76 & 0.87 & 0.75 & 1.46 & 1.49 & 1.61 & 0.114 & 0.601 & $<.0001$ & 0.212 \\
\hline $\mathrm{C} 12: 0$ & 0.72 & 0.88 & 0.71 & 1.38 & 1.49 & 1.36 & 0.129 & 0.061 & $<.0001$ & 0.892 \\
\hline C13:0 & 0.51 & 0.56 & 0.55 & 0.83 & 0.76 & 0.89 & 0.080 & 0.953 & $<.0001$ & 0.663 \\
\hline C14:0 & 1.75 & 2.01 & 2.10 & 2.40 & 2.79 & 2.51 & 0.261 & 0.055 & $<.0001$ & 0.379 \\
\hline C15:0 & 0.57 & 0.67 & 0.59 & 0.76 & 0.86 & 0.76 & 0.066 & 0.011 & $<.0001$ & 0.896 \\
\hline C16:0 & 17.2 & 16.72 & 17.54 & 17.05 & 17.06 & 17.1 & 1.041 & 0.701 & 0.889 & 0.768 \\
\hline C17:0 & 4.89 & 5.16 & 5.24 & 1.36 & 1.49 & 1.42 & 0.428 & 0.534 & $<.0001$ & 0.808 \\
\hline C18:0 & 12.9 & 12.54 & 12.50 & 11.91 & 11.87 & 12.00 & 0.824 & 0.855 & 0.036 & 0.846 \\
\hline C20:0 & 1.32 & 1.36 & 1.29 & 1.33 & 1.50 & 1.28 & 0.169 & 0.241 & 0.440 & 0.641 \\
\hline C21:0 & $0.96^{\mathrm{C}}$ & $1.04^{b c}$ & $0.89^{c}$ & $0.97^{c}$ & $1.18^{\mathrm{a}}$ & $1.09^{\mathrm{ab}}$ & 0.072 & 0.001 & $<.0001$ & 0.049 \\
\hline C22:0 & 0.91 & 1.05 & 0.91 & 1.37 & 1.48 & 1.36 & 0.168 & 0.152 & $<.0001$ & 0.974 \\
\hline \multicolumn{11}{|l|}{ Monounsaturated fatty acids } \\
\hline C14:1 & 0.41 & 0.47 & 0.48 & 0.67 & 0.72 & 0.65 & 0.076 & 0.268 & $<.0001$ & 0.398 \\
\hline C15:1 & 0.45 & 0.51 & 0.54 & 0.66 & 0.71 & 0.63 & 0.087 & 0.456 & $<.0001$ & 0.377 \\
\hline C16:1 & 1.63 & 1.73 & 1.85 & 2.15 & 2.03 & 2.25 & 0.141 & 0.040 & $<.0001$ & 0.316 \\
\hline C17:1 & $0.99^{\mathrm{b}}$ & $1.07^{\mathrm{ab}}$ & $1.25^{\mathrm{a}}$ & $1.16^{\mathrm{ab}}$ & $1.22^{\mathrm{a}}$ & $1.11^{\mathrm{ab}}$ & 0.141 & 0.274 & 0.218 & 0.047 \\
\hline tran-9 C18:1 & 0.99 & 1.00 & 1.05 & 0.99 & 1.03 & 1.01 & 0.098 & 0.779 & 0.905 & 0.905 \\
\hline cis-9 C18:1 & 39.05 & 36.82 & 36.44 & 33.10 & 32.08 & 32.74 & 1.664 & 0.132 & $<.0001$ & 0.332 \\
\hline C20:1 & 0.58 & 0.65 & 0.52 & 0.73 & 0.77 & 0.64 & 0.074 & 0.005 & $<.0001$ & 0.963 \\
\hline C24:1 & 0.50 & 0.59 & 0.52 & 0.82 & 0.80 & 0.82 & 0.125 & 0.904 & $<.0001$ & 0.639 \\
\hline \multicolumn{11}{|l|}{ n-6 Polyunsaturated fatty acids } \\
\hline$C 18: 2 n-6 c$ & 0.54 & 0.64 & 0.51 & 0.59 & 0.64 & 0.60 & 0.075 & 0.047 & 0.150 & 0.585 \\
\hline C18:2n-6t & $3.61^{c}$ & $3.64^{c}$ & $3.42^{c}$ & $7.09^{\mathrm{a}}$ & $6.04^{\mathrm{b}}$ & $6.69^{\mathrm{a}}$ & 0.423 & 0.340 & $<.0001$ & 0.007 \\
\hline C18:3n-6 & $0.56^{\mathrm{a}}$ & $0.60^{\mathrm{a}}$ & $0.60^{\mathrm{a}}$ & $0.57^{\mathrm{a}}$ & $0.61^{\mathrm{a}}$ & $0.46^{\mathrm{b}}$ & 0.051 & 0.022 & 0.061 & 0.008 \\
\hline$C 20: 2 n-6$ & $0.68^{\mathrm{ab}}$ & $0.76^{\mathrm{a}}$ & $0.73^{\mathrm{ab}}$ & $0.65^{\mathrm{b}}$ & $0.68^{\mathrm{ab}}$ & $0.50^{c}$ & 0.072 & 0.023 & 0.001 & 0.041 \\
\hline$C 20: 3 n-6$ & 0.77 & 0.78 & 0.71 & 0.82 & 0.78 & 0.72 & 0.087 & 0.119 & 0.700 & 0.834 \\
\hline$C 20: 4 n-6$ & 2.22 & 2.29 & 2.14 & 4.41 & 3.56 & 3.94 & 0.472 & 0.312 & $<.0001$ & 0.167 \\
\hline$C 22: 2 n-6$ & 0.72 & 0.95 & 0.81 & 0.61 & 0.77 & 0.76 & 0.097 & 0.011 & 0.031 & 0.302 \\
\hline \multicolumn{11}{|l|}{ n-3 Polyunsaturated fatty acids } \\
\hline C18:3n-3 & $1.39^{\mathrm{d}}$ & $1.52^{\mathrm{cd}}$ & $1.71^{\mathrm{c}}$ & $1.35^{\mathrm{d}}$ & $2.47^{\mathrm{a}}$ & $2.10^{\mathrm{b}}$ & 0.135 & $<.0001$ & $<.0001$ & $<.0001$ \\
\hline$C 20: 3 n-3$ & 0.79 & 0.91 & 0.97 & 0.63 & 0.67 & 0.59 & 0.085 & 0.150 & $<.0001$ & 0.058 \\
\hline$C 20: 5 n-3$ & 1.12 & 1.22 & 1.51 & 1.39 & 1.62 & 1.62 & 0.154 & 0.002 & 0.001 & 0.256 \\
\hline$C 22: 6 n-3$ & $0.86^{\mathrm{C}}$ & $1.04^{\mathrm{b}}$ & $1.25^{\mathrm{a}}$ & $0.77^{c}$ & $0.76^{\mathrm{c}}$ & $0.86^{\mathrm{c}}$ & 0.096 & 0.001 & $<.0001$ & 0.015 \\
\hline \multicolumn{11}{|l|}{ Sum and ratio } \\
\hline SFA & 42.47 & 42.82 & 43.01 & 40.85 & 42.00 & 41.34 & 0.900 & 0.253 & 0.001 & 0.570 \\
\hline MUFA & 44.66 & 42.83 & 42.65 & 40.28 & 39.4 & 39.85 & 1.199 & 0.050 & $<.0001$ & 0.393 \\
\hline PUFA & 12.88 & 14.35 & 14.34 & 18.87 & 18.61 & 18.81 & 1.254 & 0.492 & $<.0001$ & 0.336 \\
\hline n-3 PUFA & 4.17 & 4.69 & 5.44 & 4.14 & 5.52 & 5.17 & 0.624 & 0.003 & 0.495 & 0.206 \\
\hline n-6 PUFA & 8.71 & 9.65 & 8.91 & 14.73 & 13.09 & 13.64 & 1.079 & 0.771 & $<.0001$ & 0.077 \\
\hline n-3 LCPUFA & 2.78 & 3.16 & 3.73 & 2.78 & 3.05 & 3.07 & 0.537 & 0.089 & 0.246 & 0.432 \\
\hline
\end{tabular}


Table 3 Fatty acid profiles (percentage of total identified fatty acids methyl esters) in muscles of kids fed diets containing oil supplements (Continued)

\begin{tabular}{|c|c|c|c|c|c|c|c|c|c|c|}
\hline & \multicolumn{3}{|c|}{ Longissimus dorsi } & \multicolumn{3}{|c|}{ Biceps femoris } & \multirow{2}{*}{$\begin{array}{l}\text { SEM } \\
\text { main } \\
\text { effects }\end{array}$} & \multicolumn{3}{|l|}{$P$-value } \\
\hline & $\mathrm{PMO}$ & LSO & MIX & $\mathrm{PMO}$ & LSO & MIX & & Diet & Tissue & Diet $\times$ Tissue \\
\hline n-6 LCPUFA & 4.41 & 4.79 & 4.38 & 6.48 & 5.78 & 5.91 & 0.569 & 0.587 & $<.0001$ & 0.189 \\
\hline$n-6 / n-3$ & $2.09^{d}$ & $2.06^{d}$ & $1.64^{\mathrm{e}}$ & $3.55^{\mathrm{a}}$ & $2.37^{c}$ & $2.64^{\mathrm{b}}$ & 0.131 & $<.0001$ & $<.0001$ & $<.0001$ \\
\hline U/S & 1.35 & 1.33 & 1.33 & 1.45 & 1.38 & 1.42 & 0.079 & 0.576 & 0.019 & 0.702 \\
\hline $\mathrm{P} / \mathrm{S}$ & 0.30 & 0.34 & 0.33 & 0.46 & 0.44 & 0.46 & 0.040 & 0.754 & $<.0001$ & 0.309 \\
\hline
\end{tabular}

a,b,c,d,e Interactions of diet and tissue means within a row without a common superscript letter differ $(P<0.05)$

${ }^{1}$ SFA saturated fatty acids $(10: 0+11: 0+12: 0+13: 0+14: 0+15: 0+16: 0+17: 0+18: 0+20: 0+21: 0+22: 0+23: 0+24: 0)$, MUFA monounsaturated fatty acids (14:1 + $15: 1+16: 1+17: 1+$ tran-9 18:1 + cis-9 18:1 + 20:1 + 22:1 + 24:1), n-6 PUFA n-6 polyunsaturated fatty acids $(18: 2 n-6 t+18: 2 n-6 c+18: 3 n-6+20: 2 n-6+20: 3 n-6+20: 4 n-$ $6+22: 2 n-6), n-3$ PUFA $n-3$ polyunsaturated fatty acids (18:3n-3 + 20:3n-3 + 20:5n-3 + 22:6n-3), n-6 LCPUFA $n-6$ long chain polyunsaturated fatty acids (20:2n- $6+$ 20:3n-6 + 20:4n-6 + 22:2n-6), n-3 LCPUFA $n-3$ long chain polyunsaturated fatty acids (20:3n-3 + 20:5n-3 + 22:6n-3); n-6/n-3n-6 long chain polyunsaturated fatty acids $/ \mathrm{n}-3$ long chain polyunsaturated fatty acids; $\mathrm{P} / \mathrm{S}$ polyunsaturated fatty acids/saturated fatty acids; U/S unsaturated fatty acids/saturated fatty acids PMO palm oil diet, LSO linseed oil diet, MIX mixed oil diet

LSO-fed kids did not differ $(P \geq 0.10)$ from either PMOfed or MIX-fed kids.

\section{Bacterial diversity}

\section{Sequencing coverage and bacterial diversity}

A total of 1,336,287 reads were generated after quality control and chimera removal, resulting in an average of 74,238 reads per sample, with sequence numbers per sample ranging from 51,620 to 85,348 (median 74,632). A total of 418 unique OTUs that could be taxonomically classified to genus level were identified across all samples. The OTU rarefaction curves of the bacterial communities in the ruminal digesta show that the sampling effort was sufficient to estimate bacterial diversity (Supplementary Fig. S1). Alpha diversity indices (Table 5) indicated that supplementation did not significantly affect OTU number, ACE, Chao, Simpson, Shannon, and coverage indices $(P \geq 0.10)$.

\section{Bacterial community}

As reflected by nMDS using the weighted Unifrac similarity metric, the samples clustered according to the dietary treatments (Fig. 2). There is a clear separation between PMO and LSO (Adonis analysis, $P<0.001$ ), whereas the points for the MIX animals were spread.

\section{Spearman correlation analysis}

The 45 most abundant genera represent 91\% (PMO), $89 \%$ (LSO), and 92\% (MIX) of the total microbiome. Spearman correlation analysis was conducted between the abundance of the top 45 genera and the proportional loss rate of fatty acids (C18:3n-3 and cis-9 C18:1), or the proportional increment rate of fatty acid $(\mathrm{C} 18: 0)$ from diet to rumen (Fig. 3). The threshold $|R|>0.4$ is considered as a significant Spearman correlation. Among the top 45 genera, an unclassified genus was clustered among the genera belonging to the Bacteroidetes phylum, and was labelled 'unclassified_k_norank' by the phylogenetic analysis software (Supplementary Fig. S2).
The results indicated that relative abundance of the unclassified genera in Bacteroidetes, Succinivibrio, and Succinivibrionaceae UCG-002 were positively correlated with the rate of reduction in the proportion of cis-9 C18:1 from diet to rumen, but negatively correlated with the rate of reduction in the proportion of C18:3n-3 from diet to rumen. The relative abundance of Pseudobutyrivibrio was positively correlated with the rate of reduction in the proportion of $\mathrm{C} 18: 3 \mathrm{n}-3$, but negatively correlated with the rate of reduction in the proportion of cis-9 C18:1. For the relative abundance of Ruminococcus_2, there was a positive correlation only with the rate of increase in the proportion of C18:0 from diet to rumen.

\section{Microbial composition analysis}

Collectively, 26 bacterial phyla, 183 families, 418 genera, and 789 species were identified in the rumen samples. Independent of diets, Bacteroidetes, Firmicutes, Proteobacteria, and Verrucomicrobia were the dominant phyla (Supplementary Fig. S3), comprising about $89 \%$ of average relative abundance. The most abundant 20 families are shown in Table 6, representing 92\% (PMO), 88\% (LSO), and 94\% (MIX) of the total microbiome. The relative abundance of Bacteroidales_BS11_gut_group was greater in PMO-fed kids than in LSO-fed and MIXfed kids $(P<0.05)$, but did not differ $(P \geq 0.10)$ between LSO-fed and MIX-fed kids. The relative abundance of Veillonellaceae and Acidaminococcaceae was greater in LSO-fed kids than in PMO-fed and MIX-fed kids $(P<$ $0.05)$, but did not differ between PMO-fed and MIX-fed kids $(P \geq 0.10)$. Compared with PMO-fed kids, the relative abundance of Bacteroidales_S24-7_group was greater in MIX-fed kids $(P<0.05)$, but values for LSOfed kids did not differ $(P \geq 0.10)$ from those in either the PMO-fed or MIX-fed kids.

The centre of the ternary plot (Fig. 4) shows the core microbiome (high density of circles) across the PMO, LSO, and MIX treatments. Ternary plot analysis focuses 
Table 4 Fatty acid profiles (percentage of total identified fatty acid methyl esters) in plasma of cashmere goat kids fed diets with oil supplements

\begin{tabular}{|c|c|c|c|c|c|}
\hline \multirow[t]{2}{*}{ Fatty acid $^{1}$} & \multicolumn{3}{|l|}{ Diets } & \multirow[t]{2}{*}{ SEM } & \multirow{2}{*}{$\begin{array}{l}P- \\
\text { value }\end{array}$} \\
\hline & $\overline{P M O}$ & LSO & MIX & & \\
\hline \multicolumn{6}{|c|}{ Saturated fatty acids } \\
\hline C10:0 & 1.47 & 1.82 & 1.43 & 0.124 & 0.352 \\
\hline $\mathrm{C} 12: 0$ & 1.49 & 1.68 & 1.45 & 0.093 & 0.383 \\
\hline C13:0 & 0.63 & 0.78 & 0.69 & 0.056 & 0.438 \\
\hline C14:0 & 2.20 & 2.26 & 2.03 & 0.090 & 0.401 \\
\hline C15:0 & 1.27 & 1.21 & 1.22 & 0.094 & 0.900 \\
\hline C16:0 & $15.85^{\mathrm{a}}$ & $13.00^{b}$ & $14.31^{\mathrm{ab}}$ & 0.508 & 0.008 \\
\hline C17:0 & 1.94 & 1.83 & 1.89 & 0.079 & 0.714 \\
\hline C18:0 & 17.10 & 18.46 & 18.90 & 0.800 & 0.518 \\
\hline C20:0 & 1.62 & 1.80 & 1.46 & 0.067 & 0.133 \\
\hline C21:0 & $0.82^{\mathrm{b}}$ & $1.06^{\mathrm{a}}$ & $0.96^{\mathrm{ab}}$ & 0.038 & 0.018 \\
\hline $\mathrm{C} 22: 0$ & 1.75 & 1.80 & 1.62 & 0.091 & 0.545 \\
\hline \multicolumn{6}{|c|}{ Monounsaturated fatty acids } \\
\hline C14:1 & 1.04 & 1.07 & 0.93 & 0.073 & 0.652 \\
\hline C15:1 & 0.69 & 0.95 & 0.71 & 0.057 & 0.081 \\
\hline C16:1 & $1.69^{\mathrm{a}}$ & $1.45^{\mathrm{b}}$ & $1.61^{\mathrm{ab}}$ & 0.047 & 0.063 \\
\hline C17:1 & 1.34 & 1.28 & 1.32 & 0.091 & 0.954 \\
\hline tran-9 C18:1 & 1.62 & 1.60 & 1.49 & 0.089 & 0.772 \\
\hline cis-9 C18:1 & $22.47^{\mathrm{a}}$ & $17.91^{b}$ & $19.92^{\mathrm{ab}}$ & 0.901 & 0.035 \\
\hline C20:1n-9 & $0.74^{\mathrm{b}}$ & $1.01^{\mathrm{a}}$ & $0.71^{\mathrm{b}}$ & 0.046 & 0.012 \\
\hline$C 22: 1 n-9$ & 0.56 & 0.88 & 0.76 & 0.068 & 0.154 \\
\hline \multicolumn{6}{|c|}{ n-6 Polyunsaturated fatty acids } \\
\hline$C 18: 2 n-6 t$ & 0.95 & 1.06 & 1.10 & 0.051 & 0.514 \\
\hline$c 18: 2 n-6 c$ & 11.46 & 11.27 & 10.97 & 0.380 & 0.809 \\
\hline$C 18: 3 n-6$ & 1.00 & 1.10 & 0.91 & 0.052 & 0.195 \\
\hline$C 20: 2 n-6$ & 0.83 & 1.01 & 0.83 & 0.048 & 0.113 \\
\hline$C 20: 3 n-6$ & 1.07 & 0.92 & 0.94 & 0.034 & 0.758 \\
\hline$C 20: 4 n-6$ & 1.79 & 1.99 & 1.97 & 0.057 & 0.689 \\
\hline$C 22: 2 n-6$ & 0.81 & 0.99 & 0.80 & 0.045 & 0.168 \\
\hline \multicolumn{6}{|c|}{ n-3 Polyunsaturated fatty acids } \\
\hline$C 18: 3 n-3$ & $2.51^{\mathrm{b}}$ & $3.80^{\mathrm{a}}$ & $3.63^{\mathrm{a}}$ & 0.130 & 0.001 \\
\hline$C 20: 3 n-3$ & 0.53 & 0.83 & 0.72 & 0.046 & 0.125 \\
\hline$C 20: 5 n-3$ & $1.01^{\mathrm{b}}$ & $2.13^{\mathrm{a}}$ & $2.04^{\mathrm{a}}$ & 0.046 & 0.0001 \\
\hline$C 22: 6 n-3$ & $0.87^{\mathrm{b}}$ & $1.28^{\mathrm{a}}$ & $1.32^{\mathrm{a}}$ & 0.066 & 0.020 \\
\hline \multicolumn{6}{|l|}{ Sum and ratio } \\
\hline SFA & 46.72 & 46.68 & 46.86 & 0.743 & 0.987 \\
\hline MUFA & $30.84^{a}$ & $26.97^{b}$ & $28.23^{\mathrm{ab}}$ & 0.949 & 0.081 \\
\hline PUFA & $22.45^{b}$ & $26.38^{\mathrm{a}}$ & $25.00^{\mathrm{ab}}$ & 0.539 & 0.007 \\
\hline n-3 PUFA & $4.91^{\mathrm{b}}$ & $8.04^{a}$ & $7.71^{\mathrm{a}}$ & 0.249 & $<.0001$ \\
\hline n-6 PUFA & 17.53 & 18.34 & 17.19 & 0.567 & 0.490 \\
\hline n-3 LCPUFA & $2.40^{\mathrm{b}}$ & $4.25^{\mathrm{a}}$ & $4.09^{a}$ & 0.196 & $<.0001$ \\
\hline n-6 LCPUFA & 4.49 & 4.92 & 4.54 & 0.290 & 0.344 \\
\hline
\end{tabular}


Table 4 Fatty acid profiles (percentage of total identified fatty acid methyl esters) in plasma of cashmere goat kids fed diets with oil supplements (Continued)

\begin{tabular}{|c|c|c|c|c|c|}
\hline \multirow[t]{2}{*}{ Fatty acid ${ }^{1}$} & \multicolumn{3}{|l|}{ Diets } & \multirow[t]{2}{*}{ SEM } & \multirow{2}{*}{$\begin{array}{l}P \text { - } \\
\text { value }\end{array}$} \\
\hline & $\overline{P M O}$ & LSO & MIX & & \\
\hline$n-6 / n-3$ & $3.57^{\mathrm{a}}$ & $2.28^{b}$ & $2.23^{\mathrm{b}}$ & 0.120 & $<.0001$ \\
\hline $\mathrm{P} / \mathrm{S}$ & 0.49 & 0.58 & 0.53 & 0.026 & 0.227 \\
\hline
\end{tabular}

a,b Means within the same row followed by the same superscript are not significantly different at $P<0.05$

${ }^{1}$ SFA saturated fatty acids $(10: 0+11: 0+12: 0+13: 0+14: 0+15: 0+16: 0+17: 0+18: 0+20: 0+21: 0+22: 0+23: 0+24: 0)$, MUFA monounsaturated fatty acids $(14: 1+$ $15: 1+16: 1+17: 1+$ tran-9 18:1 + cis-9 18:1 + 20:1 + 22:1 + 24:1), n-6 PUFA n-6 polyunsaturated fatty acids $(18: 2 n-6 t+18: 2 n-6 c+18: 3 n-6+20: 2 n-6+20: 3 n-6+20: 4 n-$ $6+22: 2 n-6), n-3$ PUFA $n-3$ polyunsaturated fatty acids $(18: 3 n-3+20: 3 n-3+20: 5 n-3+22: 6 n-3), n-6$ LCPUFA n- 6 long chain polyunsaturated fatty acids (20:2n- $6+$ 20:3n-6 + 20:4n-6 +22:2n-6), n-3 LCPUFA n-3 long chain polyunsaturated fatty acids $(20: 3 n-3+20: 5 n-3+22: 6 n-3) ; n-6 / n-3 n-6$ long chain polyunsaturated fatty acids/n-3 long chain polyunsaturated fatty acids; $\mathrm{P} / \mathrm{S}$ polyunsaturated fatty acids/saturated fatty acids

$P M O$ palm oil diet, LSO linseed oil diet, MIX mixed oil diet

on the abundance of genera that show a Spearman correlation with the proportional changes of fatty acid: the rank from low to high for the total abundance of Pseudobutyrivibrio was $27.7 \%$ for PMO, 33\% for MIX, and 39.3\% for LSO, respectively; for Ruminococcus_2, the values were $26.9 \%$ for PMO, $30.9 \%$ for LSO, and $42.2 \%$ for MIX, respectively; for Succinivibrionaceae UCG-002, the values were $23 \%$ for LSO, $23.8 \%$ for MIX, and $53.1 \%$ for PMO, respectively; for unclassified genus in Bacteroidetes, the values were $17 \%$ for LSO, $28.5 \%$ for MIX, and $54.5 \%$ for PMO, respectively; for Succinivibrio, the values were $15.3 \%$ for LSO, $37.6 \%$ for MIX, and $47.1 \%$ for PMO, respectively.

\section{Discussion}

The LSO diet contained more C18:3n-3 than the MIX diet, but only the MIX diet increased muscle n-3 LCPUFA concentration to levels greater than those observed with PMO diet. These results are consistent with the literature for goats $[3,25]$ showing that the C22:6n-3 content of muscle and fat increased as dietary C18:3n-3 content increased with inclusion of palm kernel cake in the diet. For cattle, two observations are relevant: i) the muscle concentration of $\mathrm{C} 22: 6 \mathrm{n}-3$ was increased in Longissimus dorsi by feeding a diet containing both palm oil and linseed oil, but not diets containing only palm oil diet or linseed oil [26]; ii) a supplement of extruded linseed oil increased the muscle contents of $\mathrm{C} 18: 3 \mathrm{n}-3$, but not C22:6n-3 [4]. Our observations support the hypothesis that these outcomes are the result of two processes, one in the rumen and the other in muscle tissue.

\section{Mixed oil decreases the hydrogenation of dietary C18:3n-3 in rumen}

In agreement with a previous study [6], the MIX diet decreased the proportional loss rate of $\mathrm{C} 18: 3 \mathrm{n}-3$ but increased the proportional loss rate of cis-9 C18:1 compared with LSO diet, leading to an increased postruminal C18:3n-3 flow, an expectation that is consistent with the similar plasma concentrations of $\mathrm{C} 18: 3 \mathrm{n}-3$ in LSO and MIX kids.The proportional loss rate of FA reflects FA hydrogenation in the rumen [6, 22-24], evidenced by the decreased C18:3n-3 hydrogenation but increased cis-9 C18:1 hydrogenation in MIX diet compared with LSO diet. The relative abundance of Pseudobutyrivibrio was positively correlated with the rate of

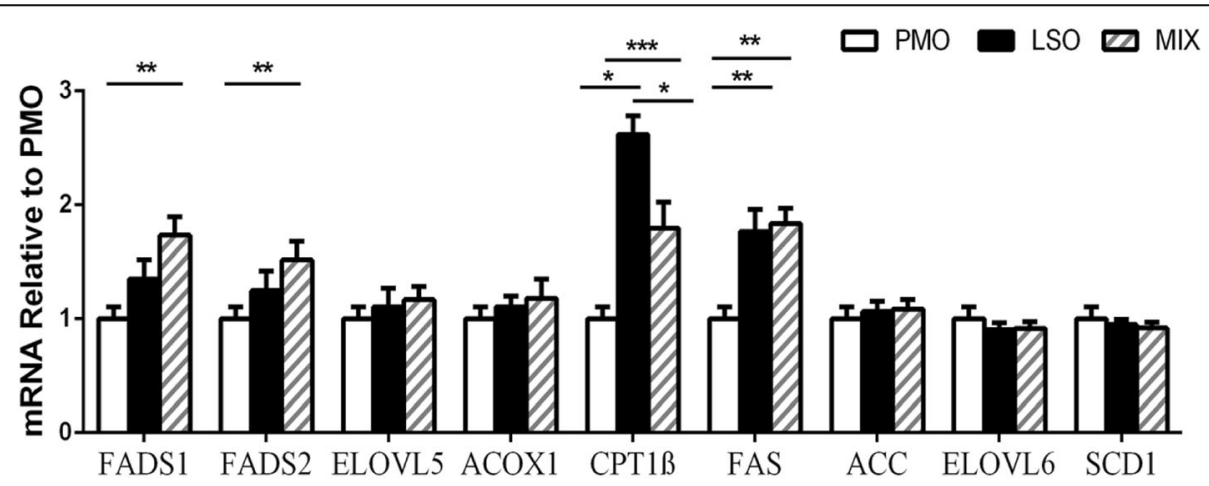

Fig. 1 Relative expression of genes related to lipid metabolism in muscle (Longissimus dorsi) of cashmere goat kids fed diets with oil supplements. PMO, palm oil diet; LSO, linseed oil diet; MIX, mixed oil diet. FAS = fatty acid synthetase, ACC = acetyl-CoA carboxylase, SCD1 = stearoyl-CoA desaturase 1, FADS1 = delta- 5 desaturase, FADS2 = delta- 6 desaturase, ELVOL5 = elongation of very long chain fatty acids protein 5 , ELOVL6 = elongation of very long chain fatty acids protein $6, A C O X 1=$ acyl-coenzyme $A$ oxidase $1, C P T 1 \beta=$ carnitine palmitoyltransferase I. ${ }^{*} P<$ $0.05,{ }^{* *} P<0.01,{ }^{* * *} P<0.001$ 
Table 5 Alpha diversity indices of ruminal bacteria in kids fed different diets

\begin{tabular}{llllll}
\hline Index & PMO & LSO & MIX & SEM & $P$-value \\
\hline Observed OTUs & 1739.5 & 1790.83 & 1790.33 & 35.57 & 0.518 \\
Shannon & 5.45 & 5.43 & 5.39 & 0.13 & 0.952 \\
Simpson & 0.02 & 0.02 & 0.02 & 0.01 & 0.658 \\
ACE & 2159.59 & 2212.18 & 2245.91 & 34.58 & 0.238 \\
Chao & 2172.17 & 2229.2 & 2267.18 & 40.01 & 0.270 \\
Good's coverage & 0.99 & 0.99 & 0.99 & 0.0002 & 0.123
\end{tabular}

PMO palm oil diet, $L S O$ linseed oil diet, MIX mixed oil diet

reduction in the proportion of dietary $\mathrm{C} 18: 3 \mathrm{n}-3$, while the relative abundances of unclassified genus in Bacteroidetes, Succinivibrionaceae UCG-002, and Succinivibrio were positively correlated with the rate of reduction in the proportion of cis9 C18:1. Except for Pseudobutyrivibrio [27], there is no direct evidence that unclassified genus in Bacteroidetes, Succinivibrionaceae UCG-002, and Succinivibrio are involved in FA hydrogenation, but these bacteria are thought to provide the energy or hydrogen needed for FA hydrogenation [28-35]. Further studies are needed to confirm the function of FA hydrogentaion of these bacteria.

At family level, Acidaminococcaceae is also involved in the hydrogenation of C18:3n-3 [36]. Veillonellaceae become the most important ruminal bacteria in goats fed a diet supplemented with linseed oil [37], suggesting that they also play an important role in the hydrogenation of dietary $\mathrm{C} 18$ : $3 n-3$, perhaps because they can provide hydrogen and energy [38].

Ternary plot analysis showed that MIX-fed kids had a lower abundance of Pseudobutyrivibrio, but greater abundance of Succinivibrionaceae UCG-002, unclassified genus in Bacteroidetes, and Succinivibrio, than LSO-fed kids. The relative abundances of the 20 most abundant bacteria (family level) showed that MIX-fed kids had a lower abundance of Acidaminococcaceae and Veillonellaceae, but greater abundance of Bacteroidales_S24-7 group, than LSO-fed kids. All of these outcomes would probably lead to a decrease in the proportional loss rate of C18:3n-3 and an increase in the proportional loss rate of cis-9 C18:1 in MIX-fed kids compared with LSO-fed kids, as observed in vitro [6].

Increases in C18:0 are a consequence of the extensive biohydrogenation in the goat rumen [5]. The abundance of Ruminococcus_2 was positively correlated with the proportional increment rate in C18:0 in the present study, which indicated that Ruminococcus_2 is related to hydrogenation, consistent with the ability of $\mathrm{H}_{2}$ production [39]. MIX-fed kids had the highest abundance of Ruminococcus_2, consistent with the high proportion of rumen C18:0 in MIXfed kids. However, PMO-fed kids had the lowest abundance of Ruminococcus_2, but the highest proportional increment rate in C18:0. The implication is that PMO-kids had a high abundance of other bacteria that are responsible for the proportional increment rate of C18:0. The inclusion of different oils in the diet did not influence bacterial richness or diversity, as reported by other laboratories [40], with Bacteroidetes, Firmicutes, Proteobacteria, and Verrucomicrobia remaining the dominant phyla for all diets, as seen in other studies with goats and sheep $[5,40]$.

The current study used proportional loss rate of FA to reflect FA biohydrogentation, and proportional increment rate in FA to reflect FA synthesis. Future research should consider more accurate calculation of the hydrogenation of FA and synthesis of FA, the passage rate, rumen volume, intake of FA, and rumen FA concentration.

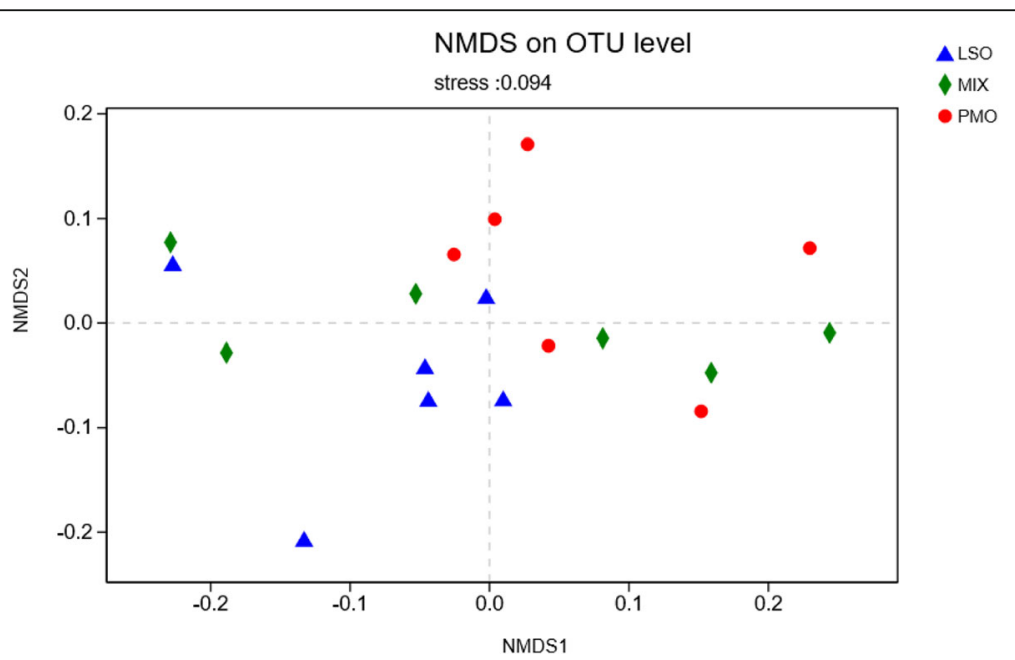

Fig. 2 Non-metric multidimensional scaling (nMDS) plot of rumen bacterial community structures. Each color represents a dietary treatment: PMO (red); LSO (blue); MIX (green) 


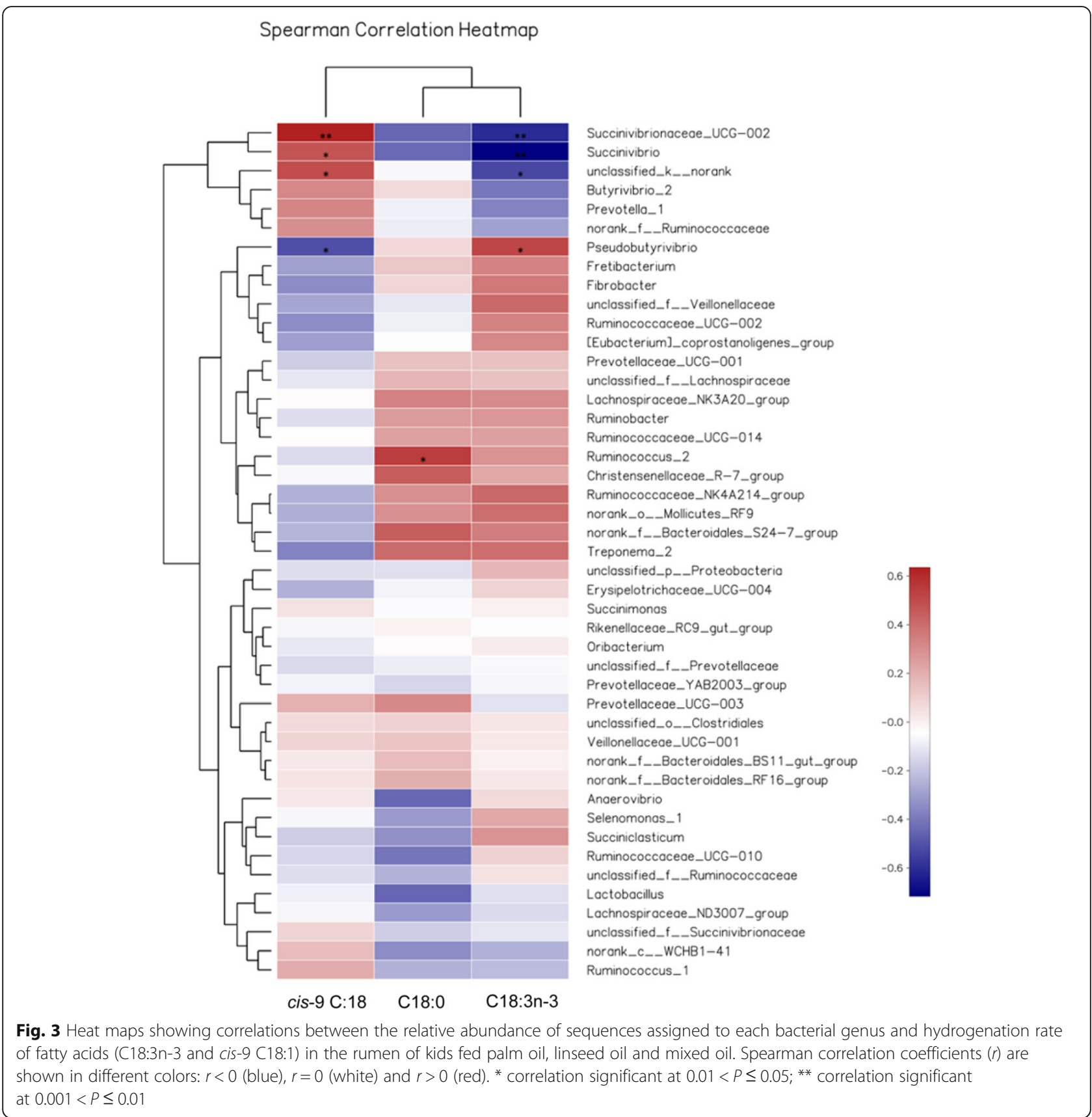

\section{Mixed oil decreases the expression of genes related to FA oxidation and increases n-3 LCPUFA content in muscle} The key enzyme involved in oxidation of FA is $C P T 1 \beta$ [41] and the most relevant enzymes in n-3 LCPUFA biosynthesis are FADS1 and FADS2 [10]. In the present study, the MIX diet decreased mRNA expression for CPT1 $\beta$ in muscle, compared with the LSO diet, thereby probably decreasing the production of the enzyme and the oxidation of $\mathrm{C} 18: 3 \mathrm{n}-3$, helping explain the increase in the muscle concentration of $\mathrm{C} 18: 3 n-3$. Moreover, if less $C 18: 3 n-3$ is oxidized, more substrate would be made available for n-3 LCPUFA synthesis, and up-regulation of mRNA expression of FADS1 and FADS2 would be observed, leading to an increase in the conversion of $\mathrm{C} 18$ : $3 n-3$ to C20:5n-3 and C22:6n-3.

Our observations are also consistent with previous studies in the goat, where a linseed oil supplement increased mRNA expression of $C P T 1 \beta$ in adipose tissue [16], and in the rabbit where mRNA expression of CPT1 in liver increased as dietary C18:3n-3 content increased [42], and palm oil decreased the TBA-reactive substances thereby improving the lipid stability of PUFA- 
Table 6 Effects of dietary oil supplements on relative abundances of the 20 most abundant bacteria (family level) in the rumen of cashmere goat kids

\begin{tabular}{|c|c|c|c|c|c|c|}
\hline Phylum & Family & $\mathrm{PMO}$ & LSO & MIX & SEM & $\boldsymbol{P}$-value \\
\hline \multirow[t]{6}{*}{ Bacteroidetes } & Prevotellaceae & 0.31 & 0.25 & 0.30 & 0.033 & 0.347 \\
\hline & Rikenellaceae & 0.06 & 0.06 & 0.07 & 0.008 & 0.599 \\
\hline & Bacteroidales_BS11_gut_group & $0.08^{\mathrm{a}}$ & $0.05^{\mathrm{b}}$ & $0.04^{b}$ & 0.009 & 0.013 \\
\hline & Bacteroidales_S24-7_group & $0.02^{b}$ & $0.03^{\mathrm{ab}}$ & $0.04^{\mathrm{a}}$ & 0.004 & 0.031 \\
\hline & Bacteroidales_RF16_group & 0.02 & 0.02 & 0.02 & 0.002 & 0.519 \\
\hline & Unclassified_f_Bacteroidetes & 0.03 & 0.02 & 0.03 & 0.006 & 0.559 \\
\hline \multirow[t]{7}{*}{ Firmicute } & Ruminococcaceae & 0.09 & 0.09 & 0.10 & 0.008 & 0.739 \\
\hline & Veillonellaceae & $0.04^{b}$ & $0.07^{\mathrm{a}}$ & $0.04^{b}$ & 0.009 & $<.001$ \\
\hline & Lachnospiraceae & 0.05 & 0.06 & 0.05 & 0.006 & 0.812 \\
\hline & Acidaminococcaceae & $0.009^{b}$ & $0.023^{\mathrm{a}}$ & $0.007^{b}$ & 0.003 & 0.012 \\
\hline & Lactobacillaceae & 0.003 & 0.002 & 0.001 & 0.001 & 0.420 \\
\hline & Erysipelotrichaceae & 0.01 & 0.01 & 0.01 & 0.001 & 0.530 \\
\hline & Christensenellaceae & 0.01 & 0.01 & 0.01 & 0.001 & 0.723 \\
\hline \multirow[t]{2}{*}{ Proteobacteria } & Succinivibrionaceae & 0.11 & 0.12 & 0.15 & 0.037 & 0.683 \\
\hline & unclassified_p_Proteobacteria & 0.002 & 0.003 & 0.002 & 0.0004 & 0.362 \\
\hline Verrucomicrobia & norank_c_WCHB1-41 & 0.03 & 0.02 & 0.03 & 0.004 & 0.420 \\
\hline Synergistetes & Synergistaceae & 0.01 & 0.02 & 0.01 & 0.002 & 0.342 \\
\hline Fibrobacteres & Fibrobacteraceae & 0.01 & 0.01 & 0.01 & 0.001 & 0.775 \\
\hline Spirochaetae & Spirochaetaceae & 0.01 & 0.01 & 0.01 & 0.001 & 0.149 \\
\hline Tenericutes & norank_O_Mollicutes_RF9 & 0.01 & 0.01 & 0.01 & 0.001 & 0.357 \\
\hline
\end{tabular}

PMO palm oil diet, $L S O$ linseed oil diet, MIX mixed oil diet

a,b Means within the same row followed by the same superscript letters are not significantly different at $P<0.05$ ( $n=6$ for each mean)

modified animal products (meat, egg and liver) [43].Taking all these findings into account, we conclude that combining linseed oil with palm oil offers a new approach for increasing the content of $\mathrm{C} 18: 3 \mathrm{n}-3$ in goat meat, and oils with a high content of PUFA can be stablised in vivo by blending them with oils of high cis-9 C18:1 content, as originally suggested by Emmison et al. [11].

\section{The effects of different dietary oils on the predominant FAs in goat muscle}

We found the predominant FAs in goat muscle to be C16:0 and C18:0 as SFAs, cis-9 C18:1 as MUFAs, and C18:2n- $6 c$ as PUFAs, as reported by Ebrahimi et al. [3]. Profiles of C16:0 in the rumen, plasma, and liver also reflect the muscle profiles, with the diets ranking $\mathrm{PMO} \geq$ MIX $\geq$ LSO, an observation from another study (Wang et al., unpublished), although muscle values did not differ significantly among these three treatments in the present study. Annison and Bryden [44] suggested that tissue C16:0 is derived from a combination of de novo synthesis and extraction from circulating plasma. Fatty acid synthetase $(F A S)$ plays a central role in de novo lipogenesis in animals by catalyzing all the reactions involved in the conversion of acetyl-coA and malonyl-CoA to palmitate [45]. Increased mRNA expression of FAS in the muscle of LSO-fed and MIX-fed kids is assumed to increase the $\mathrm{C} 16: 0$ concentration in muscle, thus nullifying the effect of the diet and explaining the lack of difference among the three groups in the muscle concentration of C16:0. In addition, ELOVL6 activity elongates $\mathrm{C} 16: 0$ and cis-9 $\mathrm{C} 16: 1$ to $\mathrm{C} 18: 0$ and cis-9 C18: 1 [46], whereas $S C D$ desaturates C18:0 to cis-9 C18:1 [47]. The results of the present study suggest that the lack of difference in mRNA expression of ELOVL6 and $S C D 1$ in muscle among the three groups would explain the similar concentrations of C16:1, C18:0, and cis-9 C18:1. Again, these observations agree with others, using various tissues, showing that linseed oil does not affect SCD1, ACC or ELOVL6 [48, 49], but increases the mRNA expression of FAS $[9,50]$.

\section{Difference in FA composition between muscle types}

In sheep, Biceps femoris typically has a lower lipid content than Longissimus dorsi whereas a muscle containing low concentrations of lipid would have a greater proportion of functional FA, such as PUFA [51, 52]. These observations explain why the concentration of PUFA was greater in Biceps femoris than in Longissimus dorsi in the present study. Working with bovine muscle, Talmant 


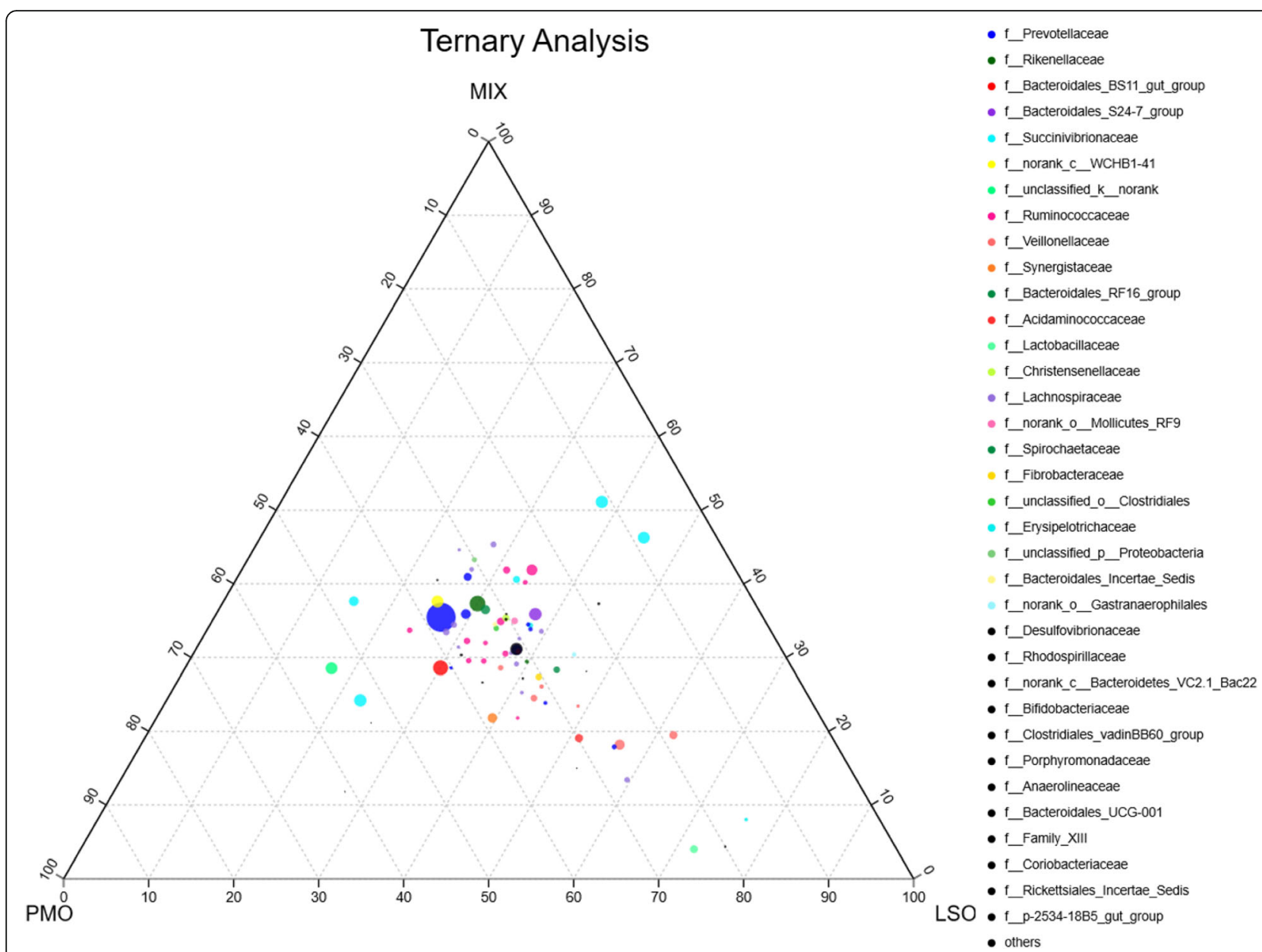

Fig. 4 Ternary plot of genus showing the percent of observations for each genus (>0.1\%) present in each dietary group (PMO, LSO, MIX). The taxonomic list at family level corresponds to genus of points. For example, a point positioned within the ' 70 ' triangle at the 'LSO' corner indicates that $70 \%$ of all observations of that genus occur within the LSO group. The diameter of plotted points corresponds to relative abundance of the genus. Each compartment of the dotted grid corresponds to a $10 \%$ increment

et al. [53] found that Longissimus dorsi has a greater glycolytic activity than Biceps femoris, implying greater production of ATP, an essential driver of de novo synthesis of SFA. In the present study, SFA concentration was greater in Longissimus dorsi than in Biceps femoris, and there was proportionately less n-6 PUFA in Longissimus dorsi than in Biceps femoris. These observations suggest that a greater glycolytic activity and a lesser mitochondrial oxidative activity lead to a lower $n-6 / n-3$ ratio in Longissimus dorsi compared with Biceps femoris. This hypothesis is supported by the observation in cattle that Biceps femoris has a greater content of PUFA, $\mathrm{P} / \mathrm{S}$, and $n-6 / n-3$ ratios, but a lesser content of SFA, compared with Longissimus dorsi [52].

\section{The interaction between oil type and muscle on $n-3$ PUFAs and $n-6$ PUFAs}

We observed that C18:3n-3 concentration was affected by both oil type and muscle type, with a lower concentration in both muscles with PMO treatment and a higher concentration in Biceps femoris with all oil treatments (expect for $\mathrm{PMO}$ ). These observations agree with other studies showing that $\mathrm{C} 18: 3 \mathrm{n}-3$ concentration is greater in Biceps femoris than in Longissimus dorsi in goats [54], and that dietary palm oil decreases C18:3n-3 concentrations in liver, adipose, and muscle of piglets, compared with linseed oil [55]. In mammals, C18:3n-3 is the subtrate for the synthesis of C22:6n-3 [4]. In Biceps femoris with both linseed-based treatments (LSO and MIX), the C18:3n-3 concentration was greater than in Longissimus dorsi with any treatment but, for C22:6n-3 concentration, the opposite outcome was observed. These observations suggest that Biceps femoris has a poor ability to synthesise C22:6n-3 from C18:3n-3 compared with Longissimus dorsi, as previously reported for goat meat [54]. Studies also demonstrated a higher C18: 2n-6 content in Biceps femoris than in Longissimus dorsi $[54,56]$. In the present study, we observed a higher C18: 
2n-6t concentratio in Biceps femoris than in Longissimus dorsi, independently of oil treatment, leading to a higher $\mathrm{n}-6 / \mathrm{n}-3$ ratio in Biceps femoris than in Longissimus dorsi.

\section{Conclusions}

Feeding a combination of linseed and palm oils (ratio of $2: 1$, weight:weight) to cashmere goat kids is an efficient method for increasing the muscle concentrations of $\mathrm{C} 18$ : 3n-3, C20:5n-3, C22:6n-3, and n-3 LCPUFA, and for decreasing the muscle $n-6 / n-3$ ratio.

\section{Supplementary information}

Supplementary information accompanies this paper at https://doi.org/10. 1186/s40104-020-00502-w.

Additional file 1: Table S1. Primer pairs sequences for quantitative real-time PCR.

Additional file 2: Figure S1. The OTU rarefaction curves of the ruminal digesta bacterial communities. Curves were drawn using the least sequenced sample as upper limit for the rarefactions. Each color represents a dietary treatment: PMO (red); LSO (blue); MIX (green).

Additional file 3: Figure S2. The approximately-maximum-likelihood phylogenetic trees revealed that unclassified_k_norank clustered within the Bacteroidetes phylum (constructed using FastTree in $\mathrm{R}$, version 2.1.3 http://www.microbesonline.org/fasttree/).

Additional file 4: Figure S3. Relative abundance of various communities of bacteria (phylum level) in the rumen of goat kids fed the palm oil (P1-P6), linseed oil (L1-L6) and mixed oil (M1-M6) diets.

\section{Abbreviations}

n-3 LCPUFA: n-3 poly-unsaturated fatty acids; FA: Fatty acid; nMDS: Nonmetric multidimensional scaling; SFA: Saturated fatty acids;

MUFA: Monounsaturated fatty acids; n-6/n-3: n-6 polyunsaturated fatty acid/ n-3 polyunsaturated fatty acid ratio; U/S: Unsaturated fatty acid/saturated fatty acid ratio; P/S: Polyunsaturated fatty acid/saturated fatty acid ratio; FAS: Fatty acid synthetase; ACC: Acetyl-CoA carboxylase; SCD1: Stearoyl-CoA desaturase 1; FADS1: Delta-5 desaturase; FADS2: Delta-6 desaturase; ELVOL5: Elongation of very long chain fatty acids protein 5; ELOVL6: Elongation of very long chain fatty acids protein 6; ACOX1: Acylcoenzyme A oxidase 1; CPT1ß: Carnitine palmitoyltransferase I; TMR: Total mixed ration

\section{Acknowledgments}

The authors gratefully acknowledge the staff of the breeding farm of AWCG in Etuoke banner of Ordos in Inner Mongolia and all members of our research group at Inner Mongolia Agriculture University.

\section{Authors' contributions}

$\mathrm{XW}$ was involved in the sample analysis, data interpretation and manuscript writing; GM was involved in manuscript writing and editing; QW, SL, YG and $Y L$ were involved in the animal experimentation; $X G, B S$ and $Y Z$ helped in collecting samples; SY designed the study and was involved in manuscript writing. All authors read and approved the final manuscript.

\section{Funding}

This study was supported by the National Science Foundation of China (Project No. 31760685) and the National Key R\&D Program of China (Project No. 2017YFD0500504)

\section{Availability of data and materials}

The raw data for the current study are available from the corresponding author on reasonable request.

\section{Ethics approval}

All procedures were approved by the Committee for the Care and Use of Animals for Experimental and other Scientific Purposes of the Inner Mongolia Agriculture University (Hohhot, Inner Mongolia, China).

\section{Consent for publication}

Not applicable.

\section{Competing interests}

The authors declare that they have no competing interests.

\section{Author details}

${ }^{1}$ Inner Mongolia Key Laboratory of Animal Nutrition and Feed Science, College of Animal Science, Inner Mongolia Agricultural University, Hohhot 010018, China. ${ }^{2}$ Beijing Advanced Innovation Center for Food Nutrition and Human Health, College of Horticulture, China Agricultural University, Beijing 100193, China. ${ }^{3}$ UWA Institute of Agriculture, The University of Western Australia, 35 Stirling Highway, Crawley, WA 6009, Australia.

Received: 7 February 2020 Accepted: 11 August 2020

Published online: 05 October 2020

\section{References}

1. Kromhout D. Fish (oil) consumption and coronary heart disease. In book: Dietary $\omega 3$ and $\omega 6$ Fatty Acids. 1989;273-282. doi:https://doi.org/10.1007/ 978-1-4757-2043-3_25.

2. Barlow SM, Young FVK, Duthie IF. Nutritional recommendations for n-3 polyunsaturated fatty acids and the challenge to the food industry. Proc Nutr Soc. 1990;49:13-21. https://doi.org/10.1079/pns19900004.

3. Ebrahimi M, Rajion MA, Goh YM. Effects of oils rich in linoleic and alinolenic acids on fatty acid profile and gene expression in goat meat. Nutrients. 2014;6:3913-28. https://doi.org/10.3390/nu6093913.

4. Gruffat D, Cherfaoui M, Bonnet M, Thomas A, Bauchart D, Durand D. Breed and dietary linseed affect gene expression of enzymes and transcription factors involved in n-3 long chain polyunsaturated fatty acids synthesis in longissimus thoracis muscle of bulls. J Anim Sci. 2013;91:3059-69. https:// doi.org/10.2527/jas.2012-6112.

5. Cremonesi P, Conte G, Severgnini M, Turri F, Monni A, Capra E, et al. Evaluation of the effects of different diets on microbiome diversity and fatty acid composition of rumen liquor in dairy goat. Animal. 2018;12:1-11. https://doi.org/10.1017/S1751731117003433.

6. Adeyemi KD, Ebrahimi M, Samsudin AA, Alimon AR, Karim R, Karsani SA, et al. Influence of Carotino oil on in vitro rumen fermentation, metabolism and apparent biohydrogenation of fatty acids. Anim Sci J. 2015;86:270-8. https://doi.org/10.1111/asj.12279.

7. Gruffat D, Gobert M, Durand D, Bauchart D. Distinct metabolism of linoleic and linolenic acids in liver and adipose tissues of finishing Normande cull cows. Animal. 2011;5:1090-8. https://doi.org/10.1017/S1751731111000073.

8. González-Ortiz G, Sala R, Cánovas E, Abed N, Barroeta AC. Consumption of dietary n-3 fatty acids decreases fat deposition and adipocyte size, but increases oxidative susceptibility in broiler chickens. Lipids. 2013;48:705-17. https://doi.org/10.1007/s11745-013-3785-3.

9. Li WH, Tang DF, Li FD, Tian HQ, Yue XP, Li F, et al. Supplementation with dietary linseed oil during peri-puberty stimulates steroidogenesis and testis development in rams. Theriogenology. 2017;102:10-5. https://doi.org/10. 1016/j.theriogenology.2017.07.002.

10. Valenzuela R, Echeverria F, Ortiz M, Rincón-Cervera MÁ, Espinosa A, Hernandez-Rodas MC, et al. Hydroxytyrosol prevents reduction in liver activity of $\Delta-5$ and $\Delta-6$ desaturases, oxidative stress, and depletion in long chain polyunsaturated fatty acid content in different tissues of high-fat diet fed mice. Lipids Health Dis. 2017;16:64. https://doi.org/10.1186/s12944-0170450-5.

11. Emmison N, Gallagher PA, Coleman RA. Linoleic and linolenic acids are selectively secreted in triacylglycerol by hepatocytes from neonatal rats. Am J Physiol-Reg I. 1995;269:R80-6.

12. China NY/T816. Feeding standard of meat-producing sheep and goats. China NongYe HangYe Biaozhun/Tuijian-816. China Agricultural Publisher, Beijing, China. 2004

13. AOAC. Official methods of analysis. 17th ed. Assoc. Off. Anal. Chem, Arlington, VA. 2002. 
14. Van Soest PJ, Robertson JB, Lewis BA. Methods for dietary fiber, neutral detergent fiber, and non-starch polysaccharides in relation to animal nutrition. J Dairy Sci. 1991;74:3583-97. https://doi.org/10.3168/jds.S00220302(91)78551-2.

15. O'Fallon JV, Busboom JR, Nelson ML, Gaskins CT. A direct method for fatty acid methyl ester synthesis: application to wet meat tissues, oils, and feedstuffs. J Anim Sci. 2007;85:1511-21. https://doi.org/10.2527/jas.2006-491.

16. Wang X, Martin GB, Liu S, Shi B, Guo X, Zhao Y, et al. The mechanism through which dietary supplementation with heated linseed grain increases n-3 long-chain polyunsaturated fatty acid concentration in subcutaneous adipose tissue of cashmere kids. J Anim Sci. 2018. https://doi.org/10.1093/ jas/sky386.

17. Wang X, Wu TM, Yan SM, Shi BL, Zhang Y, Guo XY. Influence of pasture or total mixed ration on fatty acid composition and expression of lipogenic genes of longissimus thoracis and subcutaneous adipose tissues in Albas White Cashmere Goats. Italian J Anim Sci. 2019;18:111-23. https://doi.org/10. 1080/1828051X.2018.1490632.

18. Livak KJ, Schmittgen TD. Analysis of relative gene expression data using real-time quantitative PCR and the 2- $\Delta \Delta C T$ method. Methods. 2001;25:4028. https://doi.org/10.1006/meth.2001.1262.

19. Vandesompele J, De Preter K, Pattyn F, Poppe B, Van Roy N, De Paepe A et al. Accurate normalization of real-time quantitative RT-PCR data by geometric averaging of multiple internal control genes. Genome Biol. 2002; 3:research0034-1. doi:https://doi.org/10.1186/gb-2002-3-7-research0034.

20. Evans CC, Lepard KJ, Kwak JW, Stancukas MC, Laskowski S, Dougherty J, et al. Exercise prevents weight gain and alters the gut microbiotaina mouse model of high fat diet-induced obesity. PLoS One. 2014;9:e92193. https:// doi.org/10.1371/journal.pone.0092193.

21. Caporaso JG, Kuczynski J, Stombaugh J, Bittinger K, Bushman FD, Costello EK, et al. QIIME allows analysis of high-throughput community sequencing data. Nat Methods. 2010;7:335-6. https://doi.org/10.1038/nmeth.f.303.

22. Meale SJ, Ding S, He ML, Dugan MER, Ribeiro GO Jr, Alazzeh AY, Holo H, Harstad OM, McAllister TA, Chaves AV. Effect of Propionibacterium freudenreichii, on ruminal fermentation patterns, methane production and lipid biohydrogenation of beef finishing diets containing flaxseed oil in a rumen simulation technique. Can J Anim Sci. 2014;94:685-95. https://doi. org/10.4141/CJAS-2014-051.

23. Oliveira MA, Alves SP, Santos-Silva J, Bessa RJB. Effects of clays used as oil adsorbents in lamb diets on fatty acid composition of abomasal digesta and meat. Anim Feed Sci Technol. 2016;213:64-73.

24. Alves SP, Francisco A, Costa M, Santos-Silva J, Bessa RJB. Biohydrogenation patterns in digestive contents and plasma of lambs fed increasing levels of a tanniferous bush (Cistus ladanifer L.) and vegetable oils. Animal Feed Sci Technol. 2017;225:157-72.

25. Ebrahimi M, Rajion MA, Goh YM, Sazili AQ, Schonewille JT. Effect of linseed oil dietary supplementation on fatty acid composition and gene expression in adipose tissue of growing goats. Biomed Res Int. 2013;2013:194625. https://doi.org/10.1155/2013/194625.

26. Noosen $P$, Lounglawan $P$, Suksombat W. Linseed oil supplemented concentrate fed to Brahman crossbred fattening steers on carcass quality traits and intramuscular fatty acid profiles. Songklanakarin J Sci Technol. 2017:39:1-10.

27. Cepeljnik T, Devillard E . Capability of biohydrogenation of linoleic acid in rumen bacterium Pseudobutyrivibrio xylanivorans Mz5T. Acta Agriculturae Slovenica; 2006;88:75-81.

28. Benz J, Wolf C, Rüdiger W. Chlorophyll biosynthesis: hydrogenation of geranylgeraniol. Plant Science Letters. 1980;19:225-30. https://doi.org/10. 1016/0304-4211(80)90076-0.

29. Rosenfeld IS, Tove SB. Biohydrogenation of unsaturated fatty acids VI source of hydrogen and stereospecifity of reduction. J Biol Chem. 1971;246:5025-30.

30. Hughes PE, Tove SB. Identification of an endogenous electron donor for biohydrogenation as alpha-tocopherolquinol. J Biol Chem. 1980;255:444752. https://doi.org/10.1016/S0082-0784(67)80190-5.

31. Wolin MJ, Miller TL, Stewart CS. Microbe-microbe interactions. The rumen microbial ecosystem. 1997;467-491. doi: https://doi.org/10.1007/978-1-47570322-1_10.

32. Santos EDO, Thompson F. The family succinivibrionaceae. The Prokaryotes. Springer Berlin Heidelberg. 2014;639-648. doi:https://doi.org/10.1007/0-38730743-5_20.

33. Scully ED, Geib SM, Carlson JE, Tien M, McKenna D, Hoover K. Functional genomics and microbiome profiling of the Asian longhorned beetle
(Anoplophora glabripennis) reveal insights into the digestive physiology and nutritional ecology of wood feeding beetles. BMC Genomics. 2014;15: 1096. https://doi.org/10.1186/1471-2164-15-1096.

34. Chen $H$, Zhao $R$, Wang $B$, Zheng $L$, Ouyang $H$, Wang $H$, et al. Acute oral administration of single-walled carbon nanotubes increases intestinal permeability and inflammatory responses: association with the changes in gut microbiota in mice. Adv Healthc Mater. 2018;7:e1701313. https://doi. org/10.1002/adhm.201701313.

35. Gagen EJ, Padmanabha J, Denman SE, Christopher SM. Hydrogenotrophic culture enrichment reveals rumen Lachnospiraceae and Ruminococcaceae acetogens and hydrogen-responsive Bacteroidetes from pasture-fed cattle. FEMS Microbiol Lett. 2015;14:362. https://doi.org/10.1093/femsle/fnv104.

36. Petri RM, Vahmani P, Yang HE, Dugan ME, McAllister TA. Changes in rumen microbial profiles and subcutaneous fat composition when feeding extruded flaxseed mixed with or before hay. Front Microbiol. 2018;9. https:// doi.org/10.3389/fmicb.2018.01055.

37. Wang X, Martin GB, Wen $Q$, et al. Linseed oil and heated linseed grain supplements have different effects on rumen bacterial community structures and fatty acid profiles in cashmere kids1. J Anim Sci. 2019;97: 2099-113. https://doi.org/10.1093/jas/skz079.

38. Vries de W, Rietveld-Struijk TRM, Stouthamer AH. ATP formation associated with fumarate and nitrate reduction in growing cultures of Veillonella alcalescens. Anton Leeuw Int J G 1977;43:153-167. doi:https://doi.org/10. 1007/BF00395670

39. Chaucheyras-Durand F, Masséglia S, Fonty G, Forano E. Influence of the composition of the cellulolytic flora on the development of hydrogenotrophic microorganisms, hydrogen utilization, and methane production in the rumens of gnotobiotically reared lambs. Appl Environ Microbiol. 2010;76:7931-7. https://doi.org/10.1128/AEM.01784-10.

40. Lyons T, Boland T, Storey S, Doyle E. Linseed oil supplementation of kids' diet in early life leads to persistent changes in rumen microbiome structure. Front Microbiol. 2017;8:1656. https://doi.org/10.3389/fmicb.2017.01656.

41. Paumen MB, Ishida Y, Muramatsu M, Yamamoto M, Honjo T. Inhibition of carnitine palmitoyltransferase I augments sphingolipid synthesis and palmitate-induced apoptosis. J Biol Chem. 1997;272:3324-9. https://doi.org/ 10.1074/jbc.272.6.3324.

42. Du HT, Wang CY, Wang XP, Ma MW, Li FC. The effects of dietary alinolenic acid on growth performance, meat quality, fatty acid composition, and liver relative enzyme mRNA expression of growing meat rabbits. J. Anim. Feed Sci. 2013;22:122-9. https://doi.org/10.22358/jafs/66002/2013.

43. Kang KR, Cherian G, Sim JS. Dietary palm oil alters the lipid stability of polyunsaturated fatty acid-modified poultry products. Poult Sci. 2001;80(2): 228-34. https://doi.org/10.1093/ps/80.2.228.

44. Annison EF, Bryden WL. Perspectives on ruminant nutrition and metabolism. II. Metabolism in ruminant tissues. Nutr. Res. Rev. 1999;12:147-77. https:// doi.org/10.1079/095442299108728866.

45. Weiss GH, Rosen OM, Rubin CS. Regulation of fatty acid synthetase concentration and activity during adipocyte differentiation. Studies on 3T3L1 cells. J Bio Chem. 1980;2554:751-7.

46. Jakobsson A, Westerberg $R$, Jacobsson A. Fatty acid elongases in mammals: their regulation and roles in metabolism. Prog Lipid Res. 2006;45:237-49. https://doi.org/10.1016/j.plipres.2006.01.004.

47. Vernon RG. Lipid metabolism in the adipose tissue of ruminant animals. Prog Lipid Res. 1980;19:23-106. https://doi.org/10.1016/01637827(80)90007-7.

48. Faulconnier $Y$, Bernard L, Boby C, Domagalski J, Chilliard Y, Leroux C. Extruded linseed alone or in combination with fish oil modifies mammary gene expression profiles in lactating goats. Animal. 2018;12:1564-75. https:// doi.org/10.1017/S1751731117002816.

49. Chen K, Li E, Xu C, Wang X, Lin H, Qin JG, Chen L. Evaluation of different lipid sources in diet of pacific white shrimp Litopenaeus vannamei at low salinity. Aquaculture Reports. 2015;2:163-8. https://doi.org/10.1016/j.aqrep. 2015.10.003.

50. Kim JS, Ingale S, Lee SH, Choi YH, Kim EH, Lee DC, et al. Impact of dietary fat sources and feeding level on adipose tissue fatty acids composition and lipid metabolism related gene expression in finisher pigs. Anim Feed Sci Technol. 2014;196:60-7. https://doi.org/10.1016/j. anifeedsci.2014.06.007.

51. Erkigul B, Gerelt B, Damdinsuren L. The seasonal effects on IMF content of FAS mRNA expression in muscles of Mongolian sheep. Mongolian J Agricultural Sci. 2018;21:43-8. https://doi.org/10.5564/mjas.v21i02.904. 
52. Wolf C, Ulbrich SE, Kreuzer M, Berard J, Giller K. Differential partitioning of rumen-protected $\mathrm{n}-3$ and $\mathrm{n}-6$ fatty acids into muscles with different metabolism. Meat Sci. 2018;137:106-13. https://doi.org/10.1016/j.meatsci. 2017.11.007.

53. Talmant A, Monin G, Briand M, Dadet M, Briand Y. Activities of metabolic and contractile enzymes in 18 bovine muscles. Meat Sci. 1986;18:23-40. https://doi.org/10.1016/0309-1740(86)90064-1.

54. Kiani A, Fallah R. Effects of live weight at slaughter on fatty acid composition of Longissimus dorsi and biceps femoris muscles of indigenous Lori goat. Trop Anim Health Prod. 2016;48(1):67-73. https://doi org/10.1007/s11250-015-0922-4.

55. Missotten J, De Smet S, Raes K, Doran O. Effect of supplementation of the maternal diet with fish oil or linseed oil on fatty-acid composition and expression of $\Delta 5$ - and $\Delta 6$-desaturase in tissues of female piglets. Animal. 2009;3(8):1196-204. https://doi.org/10.1017/S1751731109004455.

56. Sharma N, Gandemer G, Goutefongea R, Kowale BN. Fatty acid composition of water buffalo meat. Meat Sci. 1986;16(3):237-43. https://doi.org/10.1016/ 0309-1740(86)90029-X.

Ready to submit your research? Choose BMC and benefit from:

- fast, convenient online submission

- thorough peer review by experienced researchers in your field

- rapid publication on acceptance

- support for research data, including large and complex data types

- gold Open Access which fosters wider collaboration and increased citations

- maximum visibility for your research: over $100 \mathrm{M}$ website views per year

At $\mathrm{BMC}$, research is always in progress.

Learn more biomedcentral.com/submissions 